\title{
Active structures integrated with wireless sensor and actuator networks: a bio-inspired control framework*
}

\author{
Peng-cheng YANG, Yan-bin SHEN, Yao-zhi LUO ${ }^{\dagger *}$ \\ (Zhejiang Provincial Key Laboratory of Space Structures, Zhejiang University, Hangzhou 310058, China) \\ †E-mail: luoyz@zju.edu.cn \\ Received May 19, 2015; Revision accepted Nov. 30, 2015; Crosschecked Mar. 8, 2016
}

\begin{abstract}
One of the main problems in controlling the shape of active structures (AS) is to determine the actuations that drive the structure from the current state to the target state. Model-based methods such as stochastic search require a known type of load and relatively long computational time, which limits the practical use of AS in civil engineering. Moreover, additive errors may be produced because of the discrepancy between analytic models and real structures. To overcome these limitations, this paper presents a compound system called WAS, which combines AS with a wireless sensor and actuator network (WSAN). A bio-inspired control framework imitating the activity of the nervous systems of animals is proposed for WAS. A typical example is tested for verification. In the example, a triangular tensegrity prism that aims to maintain its original height is integrated with a WSAN that consists of a central controller, three actuators, and three sensors. The result demonstrates the feasibility of the proposed concept and control framework in cases of unknown loads that include different types, distributions, magnitudes, and directions. The proposed control framework can also act as a supplementary means to improve the efficiency and accuracy of control frameworks based on a common stochastic search.
\end{abstract}

Key words: Active structures (AS), Wireless sensor and actuator networks (WSAN), Shape control, Bio-inspired control http://dx.doi.org/10.1631/jzus.A1500109 CLC number: TU391; TU392.5

\section{Introduction}

Typical civil-engineering structures are designed mainly to be passive and static for pre-determined loads or indirect actions. Therefore, active adaption is a more challenging matter of current research for civil-engineering structures. Active control of civilengineering structures is a rising research trend, which was first introduced by Yao (1972). There are two concepts that are related to active structural control: first, active structures (AS) are structures consisting of both passive (static) members and active

\footnotetext{
${ }^{\ddagger}$ Corresponding author

* Project supported by the National Key Technology R\&D Program of China (No. 2012BAJ07B03) and the National Natural Science Foundation of China (Nos. 51178415 and 51578491)

(DiD Peng-cheng YANG, http://orcid.org/0000-0002-5149-7622; Yao-zhi LUO, http://orcid.org/0000-0002-9484-775X

(C) Zhejiang University and Springer-Verlag Berlin Heidelberg 2016
}

(dynamic) members (Soong and Manolis, 1987); second, adaptive structures are structures that can change their geometric configuration and physical properties to meet requirements in response to external stimulation (Miura and Furuya, 1988; Wada, 1990).

Although most studies of structural control focus on enhancing safety during vibration caused by earthquakes or high winds, maintaining serviceability is another important goal in this field (Zuk, 1968; Yao, 1972). In practical applications, there is often considerable uncertainty about in-service loading or conditions, which can significantly influence the serviceability of some flexible structures. Some of these structures governed by serviceability criteria are targeted as the primary focus of active structural control. Shape control of AS has been a research topic since the end of the 20th century (Kawaguchi et al., 1996; Skelton and Sultan, 1997; Sultan and Skelton, 
1997; Djouadi et al., 1998; Kanchanasaratool and Williamson, 2002). Equipped with sensors and actuators, structures are able to control their shapes to adapt themselves to changing loads or environments. Furthermore, advanced computing methods can be used to enable AS to learn, so that they can improve their performance based on previous experience.

AS usually perform actuations by adjusting member lengths. Adjustable members such as struts and cables can function through elongation or contraction of embedded actuators. To satisfy the serviceability objective, the actuations (length changes of the active members) have to be determined in shape control of AS, so that the structure can be driven to the target configuration. Approaches based mainly on stochastic search methods have been proposed to find feasible actuations (Shea et al., 2002; Domer et al., 2003b; Domer and Smith, 2005; Xu and Luo, 2008; 2009). Fest et al. (2003; 2004) designed AS prototypes with telescopic struts and proposed control strategies based on stochastic search to maintain a top-surface slope.

Being in a position to respond to external actions, AS are essentially a kind of bio-inspired system of civil structures. They have properties that are similar to those of living organisms and thus have been referred to as biomimetic structures (Veuve et al., 2014). This term does not include those civil structures whose structural shape simply mimics a natural shape. The word 'biomimetic' means that AS can interact with their environment and reproduce behavior inspired by nature. If AS are designed and equipped appropriately, bio-inspired ideas can be introduced into the control of AS (Smith, 2009a; 2009b). Thus, AS are capable of self-diagnosis, self-repair, and learning. Adam and Smith (2007a; $2007 b$; 2008) used a multi-objective approach for AS control to satisfy serviceability and additional robustness objectives. They proposed a control framework involving multi-objective search, reinforcementlearning, and self-diagnosis. This can be applied to situations of partially defined loading events. Korkmaz et al. $(2011 ; 2012)$ studied self-repair of an active tensegrity bridge to meet safety and serviceability requirements and proposed a multi-objective damage tolerance strategy using stochastic search. However, these existing control approaches are based on numerical models of AS. To some extent, the reliance on AS models limits the performance of shape control of AS because of the large amount of calculation, the long search time of control solutions, and deviations between numerical models and real physical structures.

Compared with traditional model-based control methods, model-free bio-inspired control is more distinct, self-organized, and real-time. Instead of being manipulated only by high-level control, bioinspired control strategies imitate movement patterns of animals and can be driven directly by sensing. Since the 1990s, studies on bio-inspired control have focused mainly on central pattern generator (CPG)based control methods (Ijspeert, 2008; Wu et al., 2009; Yu et al., 2014) that are suitable for locomotion control of bio-inspired robots with multiple degrees of freedom (DOFs). Some researchers have used this type of method to control the dynamic properties of AS (Bliss et al., 2008). Studies on shape control of AS using bio-inspired methods are rare, mainly due to a lack of appropriate tools.

Nowadays advances in wireless technology and smart sensor technology are creating a favorable environment for the development of civil-engineering structures. Wireless sensor network (WSN) has shown potential for structural health monitoring (SHM) (Straser and Kiremidjian, 1998; Spencer et al., 2004; Lynch, 2007), because its installation and maintenance are easier and less expensive than a wired network. In many structural applications of WSNs, however, it is not enough to observe only the structural state. The networks are expected also to respond to the sensed information by performing actions on the structure. There have been some studies of structural vibration control using WSN. These designs are mainly implemented through hydraulic dampers wired to wireless sensor nodes (Wang et al., 2007; Swartz and Lynch, 2009; Wang and Law, 2011). However, WSNs usually work only as passive devices for most of civil-engineering structures.

Actuators that are capable of wireless communication can be incorporated into WSN to form a wireless sensor and actuator network (WSAN) (Akyildiz and Kasimoglu, 2004; Stankovic, 2008; Atzori et al., 2010). WSANs consist of groups of sensors and actuators that are connected to a wireless 
medium. Sensors serve to detect information about the physical world, while actuators can perform appropriate actions to affect the physical world according to the sensory information. WSANs are closed-loop systems that can interact with the physical world automatically. In recent years, researchers started to use WSANs for centralized or decentralized control systems (Chen et al., 2008; 2010; Cao et al., 2010).

Being able not only to observe but also to respond, AS is a conceptual extension of SHM, and in the same way, WSAN is an extension of WSN. Moreover, WSANs can be the best choice for active structural control, because the entire control system can perform via easily deployed devices. They can also be potentially applied to spatially distributed control units embedded in the structure, especially for AS whose members unite spatially. However, few studies of AS using WSANs have been published.

This paper presents the concept of a compound system named WAS (short for WSAN-AS) which consists of an AS and embedded WSAN. The concept treats AS and WSAN equally and considers them as a whole, and its core principle is that the structural arrangement should harmonize with the topology of wireless hardware devices. Moreover, to overcome the limitation of previous work on shape control of AS, a two-hierarchy bio-inspired control framework is proposed for WAS to give immediate response to unknown loads.

In this paper, the concept and the modeling of WAS are described first. Then the control framework is introduced. At last, a simple example of WAS is given to illustrate the concept and validate the framework.

\section{Concept and basic model}

\subsection{Motivation and difficulty}

As stated above, existing studies on AS have obtained shape control solutions mainly by stochastic searches. In each search process, the computer has to generate adequate samples of actuation results for a single solution. In each calculation process, the computer has to solve nonlinear finite-elementmethod (FEM) problems repetitively to evaluate (or to predict) the state of AS and get an actuation result through a numerical method, such as dynamic relaxation (Fest et al., 2003). In short, to generate effective solutions, substantial search work has to be done. That can place several limitations on the practical applications of AS:

1. It is sometimes difficult to implement realtime control. Without case-base or any learning methods, it takes a relatively long time to give an effective solution in response to a new loading event (Shea et al., 2002; Smith, 2003; Fest et al., 2004). It is long even for quasi-static control, not to mention for real-time control. With an ordinary low-cost computer, there can be a heavy computational burden, especially in the case of a relatively complex structure.

2. The system may not have sufficient reliability. On the whole, the computer has to manage all the computation, communication, and coordination works to keep the system running. If, by any chance, the computer happens to crash (actually not uncommon), the entire system will break down.

3. Adaptability to loads can sometimes be limited. In those model-based stochastic search procedures for the numerical FEM calculation, the load conditions have to be known or prescribed to the computer or the human controllers (the users) (Shea et al., 2002; Fest et al., 2003; 2004), or at least the load has to be partially defined so that the load identification work can be done first (Adam and Smith, 2007a; 2008). In situations where the only piece of information is the structural deformation (from totally unknown loads), the control task will be difficult.

4. There may be the influence of discrepancy between the calculation and the physical world. The computational process relies on the numerical FEM model and other assumptions. In fact, construction of real structures cannot be $100 \%$ the same as the blueprint, and structural damage or loss of pre-stress also makes a physical structure deviate from the numerical design model. Researchers have considered this issue and offered some solutions. For example, calibration of a numerical model with a correction based on measurements (Shea et al., 2002; Fest et al., 2003) or an artificial neural network (ANN) used to modify numerical models (Domer et al., 2003a) may help reduce the discrepancy, locate some simple structural damage (Adam and Smith, 2006), and identify 
self-stress to some extent (Angellier et al., 2012). Nevertheless, the effect and generality of such measures are limited. The difference between the numerical model and the real structure can often affect the accuracy of control in experimental tests or the practical application of AS, not to mention the limitation of the accuracy of actuators.

By contrast, bio-inspired methods for locomotion control in the field of robotics are rather attractive for the shape control of AS (Table 1). However, applying bio-inspired methods to shape control of AS is not that easy. Unlike multi-degree-of-freedom (multiDOF) robots, such as multi-legged robots, AS are geometrically stable, and they are always statically determinate or indeterminate during the in-service period. All members of AS unite as a whole and interact with each other. A slight move in one active member can cause redistribution of the internal forces of all the members, and it definitely affects the shape of the entire structure. This means the correlation between each DOF of AS is more significant, and AS cannot change the shape (or configuration) as casually as robots do. Meanwhile, all the actuators and sensors are fixed-wired to the central computer, and the centralized one-to-many relation is not suitable for distributed control of bio-inspired methods. This precludes AS from behaving as flexibly as robots.

\subsection{Definition and formulas}

A WSAN is used to enhance AS. WSAN is not a simple superposition of WSN and wireless actuators. Instead, it is heterogeneous and closed-loop, while WSN is homogeneous and open-loop. The feature of WSAN is cooperative communication and control.

As the medium and functional component, WSAN is embedded in AS. This integrated system that consists of AS and WSAN is abbreviated to WAS. It is intended to be a bio-inspired compound system. In WAS, the role of WSAN is the 'nervous system' that coordinates the activity of the 'muscles' (actuators) and processes the input from the sensors. With the wireless 'nerve fibers', the 'nervous system' of WAS can be self-organized, and it can change its topology to adapt to different situations.

As the 'skeletons' and 'tendons' of WAS, the arrangement of structural members should be compatible with the 'nervous system' and 'muscles'. In a word, all the components of WAS should be designed to harmonize with each other. Taking cable-strut structures as example, the physical process of WAS can be described as the following four parts:

$$
\begin{gathered}
\boldsymbol{M} \ddot{\boldsymbol{D}}=\boldsymbol{F}_{\mathrm{i}}+\boldsymbol{F}_{\mathrm{e}}, \\
\boldsymbol{S}=\boldsymbol{\Lambda}_{\mathrm{s}} \boldsymbol{P}+\boldsymbol{\Gamma}_{\mathrm{s}}, \\
\Delta \boldsymbol{A}=\boldsymbol{\Omega}_{\mathrm{a}} \boldsymbol{C} \boldsymbol{\Omega}_{\mathrm{s}} \boldsymbol{S}+\boldsymbol{\Gamma}_{\mathrm{a}}, \\
\boldsymbol{L}_{\mathrm{r}}=\boldsymbol{L}_{\mathrm{r}, \mathrm{o}}+\boldsymbol{\Lambda}_{\mathrm{a}} \boldsymbol{A},
\end{gathered}
$$

where all structural members are uniaxial elements with three DOFs at each node, struts are tensioncompression members, and cables are tension-only members. Here are some details of expressions (1)-(4).

The mechanical process (1) is expressed as Newton's second law of motion, where $\boldsymbol{M}$ is $n_{\mathrm{n}} \times n_{\mathrm{n}}$ mass matrix of structural nodes, and $n_{\mathrm{n}}$ is the number of all the structural nodes. $\boldsymbol{M}$ can be expressed as

$$
\boldsymbol{M}=\operatorname{diag}\left(\ldots, m_{k}, \ldots\right)
$$

where $m_{k}$ is the equivalent mass of the $k$ th structural node $\left(k \in\left\{1,2, \ldots, n_{\mathrm{n}}\right\}\right) . \boldsymbol{D}$ is $n_{\mathrm{n}} \times 3$ displacement

Table 1 Comparison between model-based and bio-inspired approaches

\begin{tabular}{lcc}
\hline \multirow{2}{*}{ Item } & \multicolumn{2}{c}{ Description } \\
\cline { 2 - 3 } & Model-based approach & Bio-inspired approach \\
\hline Motion description & FEM model & Connection between functional units \\
Pattern & High-level control & High-level control \& awareness \\
Behavior & Precise & Instant \\
Method complexity & Complex & Simple \\
Error source & Modeling, calibration \& control & Control \\
Real-time performance & Slow (if without any cases) & Fast \\
Dependence on central computer & Strong & Ordinary (or none) \\
\hline
\end{tabular}


matrix of structural nodes, and

$$
\boldsymbol{D}=\left[\ldots, \boldsymbol{d}_{k}, \ldots\right]^{\mathrm{T}},
$$

where $\boldsymbol{d}_{k}$ is displacement vector of the $k$ th structural node $\left(k \in\left\{1,2, \ldots, n_{\mathrm{n}}\right\}\right)$, and

$$
\boldsymbol{d}_{k}=\left[d_{x, k}, d_{y, k}, d_{z, k}\right]^{\mathrm{T}}
$$

$\ddot{\boldsymbol{D}}$ is $n_{\mathrm{n}} \times 3$ acceleration matrix of structural nodes. $\boldsymbol{F}_{\mathrm{i}}$ is $n_{\mathrm{n}} \times 3$ internal force matrix of structural nodes and can be determined by

$$
\boldsymbol{F}_{\mathrm{i}}=\boldsymbol{\Lambda}_{\mathrm{t}} \hat{\boldsymbol{F}}_{\mathrm{a}} \boldsymbol{D}_{\mathrm{c}}
$$

where $\boldsymbol{\Lambda}_{\mathrm{t}}$ is $n_{\mathrm{n}} \times n_{\mathrm{m}}$ layout matrix of structural topology and $n_{\mathrm{m}}$ is the number of all the structural members. $\boldsymbol{\Lambda}_{\mathrm{t}}$ can be expressed as

$$
\Lambda_{\mathrm{t}}=\left\{\lambda_{\mathrm{t}, i, j}\right\}
$$

where $i \in\left\{1,2, \ldots, n_{\mathrm{n}}\right\}$, and $j \in\left\{1,2, \ldots, n_{\mathrm{m}}\right\}$. If the $i$ th node is the starting point of the $j$ th member, $\lambda_{\mathrm{t}, i, j}=1$; or if the $i$ th node is the ending point of the $j$ th member, $\lambda_{\mathrm{t}, i, j}=-1$; otherwise, $\lambda_{\mathrm{t}, i, j}=0 . \boldsymbol{F}_{\mathrm{a}}$ is $n_{\mathrm{m}} \times 1$ axial force vector of the structural members, and

$$
\boldsymbol{F}_{\mathrm{a}}=\left[\ldots, f_{\mathrm{a}, k}, \ldots\right]^{\mathrm{T}},
$$

where $f_{\mathrm{a}, k}$ is the axial force of the $k$ th structural member $\left(k \in\left\{1,2, \ldots, n_{\mathrm{m}}\right\}\right) . \hat{\boldsymbol{F}}_{\mathrm{a}}$ is the $n_{\mathrm{m}} \times n_{\mathrm{m}}$ diagonal form of $\boldsymbol{F}_{\text {a }}$, i.e.,

$$
\hat{\boldsymbol{F}}_{\mathrm{a}}=\operatorname{diag}\left(\ldots, f_{\mathrm{a}, k}, \ldots\right),
$$

where $k \in\left\{1,2, \ldots, n_{\mathrm{m}}\right\} . \boldsymbol{D}_{\mathrm{c}}$ is $n_{\mathrm{m}} \times 3$ direction cosine matrix of structural members, and

$$
\boldsymbol{D}_{\mathrm{c}}=\left[\ldots, \boldsymbol{d}_{\mathrm{c}, k}, \ldots\right]^{\mathrm{T}},
$$

where $\boldsymbol{d}_{\mathrm{c}, k}$ is the direction cosine of the $k$ th structural member $\left(k \in\left\{1,2, \ldots, n_{\mathrm{m}}\right\}\right)$, and

$$
\boldsymbol{d}_{\mathrm{c}, k}=\left[d_{\mathrm{c}, x, k}, d_{\mathrm{c}, y, k}, d_{\mathrm{c}, z, k}\right]^{\mathrm{T}}
$$

$\boldsymbol{F}_{\mathrm{e}}$ is $n_{\mathrm{n}} \times 3$ external force matrix of structural nodes, and

$$
\boldsymbol{F}_{\mathrm{e}}=\boldsymbol{F}_{1}+\boldsymbol{F}_{\mathrm{d}}+\boldsymbol{F}_{\mathrm{r}}
$$

$\boldsymbol{F}_{1}$ is $n_{\mathrm{n}} \times 3$ load matrix of structural nodes, and

$$
\boldsymbol{F}_{1}=\left[\ldots, \boldsymbol{f}_{1, k}, \ldots\right]^{\mathrm{T}},
$$

where $f_{1, k}$ is the load vector of the $k$ th structural node $\left(k \in\left\{1,2, \ldots, n_{\mathrm{n}}\right\}\right)$, and

$$
\boldsymbol{f}_{1, k}=\left[f_{1, x, k}, f_{1, y, k}, f_{1, z, k}\right]^{\mathrm{T}}
$$

$\boldsymbol{F}_{\mathrm{d}}$ and $\boldsymbol{F}_{\mathrm{r}}$ are $n_{\mathrm{n}} \times 3$ damping force matrix and $n_{\mathrm{n}} \times 3$ support reaction force matrix of structural nodes, respectively.

In the sampling process (2), the sensors measure the structural physical quantities, such as deformation or internal forces. $\boldsymbol{S}$ is $n_{\mathrm{s}} \times 1$ vector of sampled data of sensors, and $n_{\mathrm{s}}$ is the number of all the sensors. $\boldsymbol{S}$ can be expressed as

$$
\boldsymbol{S}=\left[\ldots, s_{k}, \ldots\right]^{\mathrm{T}},
$$

where $s_{k}$ is the effective feedback of the $k$ th sensor $\left(k \in\left\{1,2, \ldots, n_{\mathrm{s}}\right\}\right), \boldsymbol{P}$ is $n_{\mathrm{p}} \times 1$ vector of measurable physical quantities, and $n_{\mathrm{p}}$ is the number of all the measurable physical quantities. Usually,

$$
\boldsymbol{P}=\left[\overline{\boldsymbol{D}}^{\mathrm{T}}, \boldsymbol{F}_{\mathrm{a}}^{\mathrm{T}}\right]^{\mathrm{T}},
$$

where $\overline{\boldsymbol{D}}$ is the $3 n_{\mathrm{n}} \times 1$ single-column form of $\boldsymbol{D}$, and

$$
\begin{gathered}
\overline{\boldsymbol{D}}=\left[\ldots, \boldsymbol{d}_{k}^{\mathrm{T}}, \ldots\right]^{\mathrm{T}}, \\
n_{\mathrm{p}}=3 n_{\mathrm{n}}+n_{\mathrm{m}} .
\end{gathered}
$$

$\Lambda_{\mathrm{s}}$ is $n_{\mathrm{s}} \times n_{\mathrm{p}}$ layout matrix of sensors, and

$$
\Lambda_{\mathrm{s}}=\left\{\lambda_{\mathrm{s}, i, j}\right\}
$$

where $i \in\left\{1,2, \ldots, n_{\mathrm{s}}\right\}$, and $j \in\left\{1,2, \ldots, n_{\mathrm{p}}\right\}$. If the $i$ th sensor is deployed on the $j$ th physical quantity, $\lambda_{\mathrm{s}, i_{i}}=1$; otherwise, $\lambda_{\mathrm{s}, i, j}=0 . \boldsymbol{S}$ can be influenced by the noise $\boldsymbol{\Gamma}_{\mathrm{s}}$, which is $n_{\mathrm{s}} \times 1$ measurement noise vector of sensors. 
In the control process (3), with the feedback received from $\boldsymbol{S}$, the controllers calculate and transmit the output to the actuators. $\boldsymbol{A}$ is $n_{\mathrm{a}} \times 1$ vector of actual actuations of actuators, and $n_{\mathrm{a}}$ is the number of all the actuators. $\boldsymbol{A}$ can be expressed as

$$
\boldsymbol{A}=\left[\ldots, a_{k}, \ldots\right]^{\mathrm{T}},
$$

where $a_{k}$ is the length adjustment of the $k$ th actuator $\left(k \in\left\{1,2, \ldots, n_{\mathrm{a}}\right\}\right) . \Delta \boldsymbol{A}$ is the increment of $\boldsymbol{A} . \boldsymbol{C}$ is $n_{\mathrm{a}} \times n_{\mathrm{S}}$ transfer matrix of controllers. $\boldsymbol{\Omega}_{\mathrm{a}}$ and $\boldsymbol{\Omega}_{\mathrm{s}}$ are $n_{\mathrm{a}} \times n_{\mathrm{a}}$ wireless transmission matrix of actuations and $n_{\mathrm{s}} \times n_{\mathrm{s}}$ wireless transmission matrix of sensor feedback, respectively. They can be expressed as

$$
\begin{aligned}
& \boldsymbol{\Omega}_{\mathrm{a}}=\operatorname{diag}\left(\ldots, \omega_{\mathrm{a}, k}, \ldots\right), \\
& \boldsymbol{\Omega}_{\mathrm{s}}=\operatorname{diag}\left(\ldots, \omega_{\mathrm{s}, k}, \ldots\right) .
\end{aligned}
$$

If the $k$ th $\left(k \in\left\{1,2, \ldots, n_{\mathrm{a}}\right\}\right)$ actuator receives wireless instruction, $\omega_{\mathrm{a}, k}=1$; otherwise, $\omega_{\mathrm{a}, k}=0$. If the data packet of the $k$ th $\left(k \in\left\{1,2, \ldots, n_{\mathrm{s}}\right\}\right)$ sensor is not lost, $\omega_{\mathrm{s}, k}=1$; otherwise, $\omega_{\mathrm{s}, k}=0 . \boldsymbol{\Gamma}_{\mathrm{a}}$ is $n_{\mathrm{a}} \times 1$ movement error vector of actuators.

In the performing process (4), the rest lengths of the active members are determined by actuations. $\boldsymbol{L}_{\mathrm{r}}$ is $n_{\mathrm{m}} \times 1$ rest length vector of structural members, and

$$
\boldsymbol{L}_{\mathrm{r}}=\left[\ldots, l_{\mathrm{r}, k}, \ldots\right]^{\mathrm{T}},
$$

where $k \in\left\{1,2, \ldots, n_{\mathrm{m}}\right\}$, and $l_{\mathrm{r}, k}$ is the rest length of the $k$ th structural member. $\boldsymbol{L}_{\mathrm{r}, \mathrm{o}}$ is the original $\boldsymbol{L}_{\mathrm{r}}$ at the initial state. $\boldsymbol{\Lambda}_{\mathrm{a}}$ is $n_{\mathrm{a}} \times n_{\mathrm{m}}$ layout matrix of actuators, and

$$
\Lambda_{\mathrm{a}}=\left\{\lambda_{\mathrm{a}, i, j}\right\},
$$

where $i \in\left\{1,2, \ldots, n_{\mathrm{a}}\right\}$, and $j \in\left\{1,2, \ldots, n_{\mathrm{m}}\right\}$. If the $i$ th actuator is embedded on the $j$ th member, $\lambda_{\mathrm{a}, i, j}=1$; otherwise, $\lambda_{\mathrm{a}, i, j}=0$. Thus, the structural internal forces, i.e., the axial forces,

$$
F_{\mathrm{a}}=\boldsymbol{A}_{\mathrm{c}} E E_{\mathrm{a}}
$$

change with the actuations, where $\boldsymbol{A}_{\mathrm{c}}$ is $n_{\mathrm{m}} \times n_{\mathrm{m}}$ cross-section area matrix of structural members, $\boldsymbol{E}$ is $n_{\mathrm{m}} \times n_{\mathrm{m}}$ elastic modulus matrix of structural members, and $\boldsymbol{E}_{\mathrm{a}}$ is $n_{\mathrm{m}} \times 1$ axial strain vector of structural members. They can be expressed as

$$
\begin{gathered}
\boldsymbol{A}_{\mathrm{c}}=\operatorname{diag}\left(\ldots, a_{\mathrm{c}, k}, \ldots\right), \\
\boldsymbol{E}=\operatorname{diag}\left(\ldots, e_{k}, \ldots\right), \\
\boldsymbol{E}_{\mathrm{a}}=\left[\ldots, \varepsilon_{\mathrm{a}, k}, \ldots\right]^{\mathrm{T}},
\end{gathered}
$$

where $k \in\left\{1,2, \ldots, n_{\mathrm{m}}\right\}$, and $a_{\mathrm{c}, k}, e_{k}$, and $\varepsilon_{\mathrm{a}, k}$ are the cross-section area, the elastic modulus, and the axial strain of the $k$ th structural member, respectively. $\boldsymbol{E}_{\text {a }}$ can be influenced by $\boldsymbol{L}_{\mathrm{r}}$ via

$$
\boldsymbol{E}_{\mathrm{a}}=\boldsymbol{\Phi}_{\mathrm{c}}\left(\ln \boldsymbol{L}-\ln \boldsymbol{L}_{\mathrm{r}}\right)
$$

where $\boldsymbol{L}$ is $n_{\mathrm{m}} \times 1$ length vector of structural members, and

$$
\boldsymbol{L}=\left[\ldots, l_{k}, \ldots\right]^{\mathrm{T}},
$$

where $l_{k}$ is the current length of the $k$ th structural member $\left(k \in\left\{1,2, \ldots, n_{\mathrm{m}}\right\}\right)$. $\boldsymbol{\Phi}_{\mathrm{c}}$ is $n_{\mathrm{m}} \times n_{\mathrm{m}}$ amendment matrix of cable members, and

$$
\boldsymbol{\Phi}_{\mathrm{c}}=\operatorname{diag}\left(\ldots, \phi_{\mathrm{c}, k}, \ldots\right)
$$

where $k \in\left\{1,2, \ldots, n_{\mathrm{m}}\right\}$. If the $k$ th member is a cable and $l_{\mathrm{k}}<l_{\mathrm{r}, k}, \phi_{\mathrm{c}, k}=0$; otherwise, $\phi_{\mathrm{c}, k}=1$.

\subsection{Discretization in the time domain}

From the perspective of control theory, WAS can drive the structure to reach requirements step by step by analyzing the measurements reported by the sensors, and each step can be interpreted as a step of control. Meanwhile, according to Section 2.2, WAS is a non-linear time variant system. If it is assumed that there is no time delay in control, the state-space expression of WAS can be described as a discrete form:

$$
\begin{gathered}
\boldsymbol{P}(t)=f\left(\boldsymbol{P}^{k-1}, \Delta \boldsymbol{A}^{k-1}, t\right), \\
\boldsymbol{P}^{k}=\boldsymbol{P}\left(t^{k}\right), \\
\boldsymbol{S}^{k}=\boldsymbol{\Lambda}_{\mathrm{s}} \boldsymbol{P}^{k}+\boldsymbol{\Gamma}_{\mathrm{s}}\left(t^{k}\right),
\end{gathered}
$$

where $k$ means the $k$ th control step, and $t$ means time. Eq. (36) comes from Eq. (2). Function $f$ is a general description related to Eqs. (1) and (4) which are 
continuous mechanical processes in the time domain. Thus, the time of the mechanical process is subdivided into equal time intervals (or time steps), $\Delta t$, and Eq. (34) can be rewritten as

$$
\boldsymbol{P}(t)=g\left(\boldsymbol{P}(t-\Delta t), \ldots, \boldsymbol{P}\left(t^{k-1}\right), \Delta \boldsymbol{A}^{k-1}, \Delta t\right)
$$

The control output is determined by Eq. (3), and for the $k$ th control step,

$$
\Delta \boldsymbol{A}^{k}=\boldsymbol{\Omega}_{\mathrm{a}}\left(t^{k}\right) \boldsymbol{C}^{k} \boldsymbol{\Omega}_{\mathrm{s}}\left(t^{k}\right) \boldsymbol{S}^{k}+\boldsymbol{\Gamma}_{\mathrm{a}}\left(t^{k}\right),
$$

and

$$
\boldsymbol{A}^{k}=\boldsymbol{A}^{k-1}+\Delta \boldsymbol{A}^{k}
$$

Fig. 1 is an illustration of one ordinary control step. Some parameters of time are considered, such as time cost of wireless transmission $t_{\mathrm{w}}$, time duration of sensor sampling $t_{\mathrm{s}}$, time duration of actuator performing $t_{\mathrm{a}}$, and response time of controller $t_{\mathrm{c}}$. In addition, $t_{\mathrm{p}}$ is the total time of the control step, $f_{\mathrm{s}}$ is the sampling frequency of sensors, and $v_{\mathrm{a}}$ is the performing velocity of actuators (i.e., the velocity of length changing of an active member).

In fact, function $g$ in Eq. (37) is not required to contain those arguments. From the point of computation, the equation of motion (1) can be solved by a simple explicit time integration, such as the central difference method (Bathe and Wilson, 1976; Luo and Yang, 2014; Yang et al., 2014). The variation of nodal displacement is assumed to consist of a series of straight-line segments, and the nodal velocity between two time points is assumed to be constant (Fig. 1). The abrupt change of the velocity at each time point is caused by an acceleration pulse. According to the central difference method, the nodal displacement can be calculated through the recursion:

$$
\boldsymbol{D}(t+\Delta t)=2 \boldsymbol{D}(t)-\boldsymbol{D}(t-\Delta t)+\ddot{\boldsymbol{D}}(t) \Delta t^{2},
$$

where the time step $\Delta t$ should be below the critical value for integration stability (Belytschko et al., 2000).

\section{Two-hierarchy control}

\subsection{A bio-inspired control framework: reflex}

As stated in Sections 1 and 2.1, for bio-inspired control in robotics, CPG-based control methods are commonly applicable to the locomotion (or gait) of multi-legged robots, but they are not suitable for shape control of AS. As mentioned in Section 2.2, WAS is a new concept that means the AS is embedded with a WSAN. It can model itself after animals by developing a bio-inspired self-control mechanism (architecture) which takes WSAN as its 'nervous system' (Fig. 2).

Here are some details about how the architecture imitates animals:

1. The nervous system of animals is commonly divided into a central nervous system (CNS) and a peripheral nervous system (PNS). CNS is divided into brain and spinal cord. CNS and PNS are connected to each other through nerve fibers. Sensory receptors and muscles are connected with the nervous system (Morris and Fillenz, 2003). Similarly, as Fig. 2 shows,

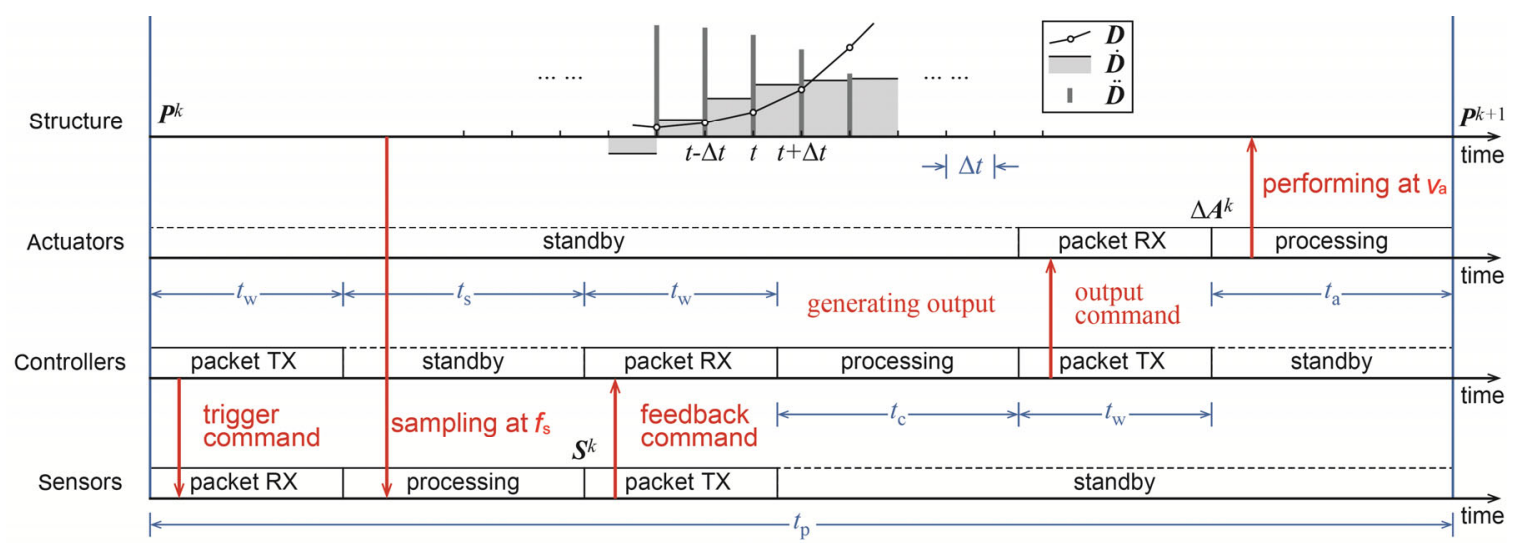

Fig. 1 Discretization of the $k$ th control step (TX means transmission, and RX means reception) 
WSAN consists of one single central controller (CC) and groups of distributed actuators and sensors (DAs and DSs). Usually, the CC and the DAs are resourcerich devices with more energy and better processing capabilities than DSs (IEEE Computer Society, 2011). Thus, the CC is assigned to be the higher level of 'CNS', i.e., the 'brain'. The DAs are the 'muscles', and their processing units play the role of spinal cord. The DSs represent the 'sensory receptors' and the ending of 'PNS'. Meanwhile, all these components communicate with each other via wireless pathways, the 'nerve fibers'.

2. The motor system of animals is a distributed organization. Sensory information relating to movement is processed in different circuits that work in parallel. The circuits that process sensory inputs and commands to muscles are distributed in the spinal cord. Each circuit can organize specific motor responses through its input and output connections (Kandel, 2013). Likewise, the WSAN contains multiple parallel personal area networks (PANs) as the 'response circuits' (Fig. 2). The PANs are connected to the $\mathrm{CC}$ directly or indirectly, and they can also communicate with each other. As the PAN coordinators, the DAs are in charge of the responses. The connection and input-output relation of DAs and DSs in each PAN can be different and relatively independent from the other PANs.

3. Locomotion of animals is hierarchically controlled by the CNS from the brain to the spinal cord

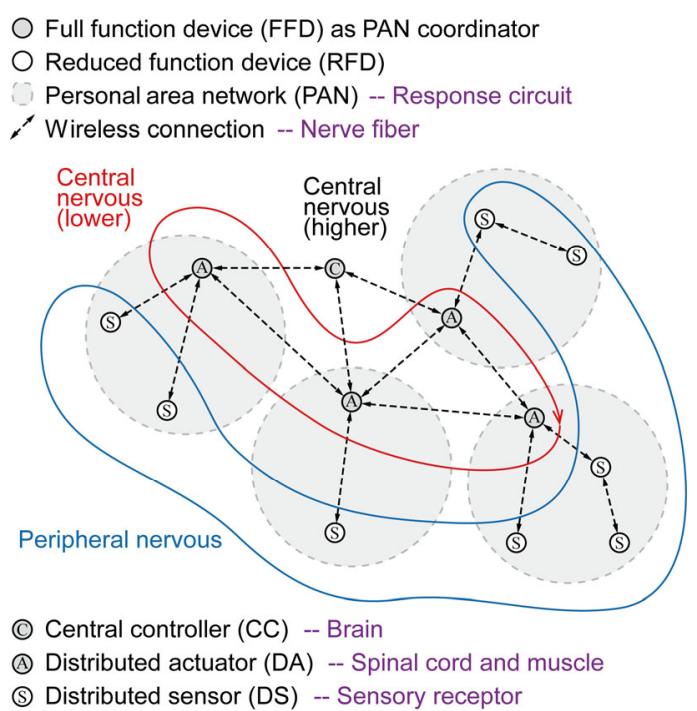

Fig. 2 Bio-inspired architecture of WSAN materialized with IEEE Standard 802.15.4 level (Delcomyn, 1980). The spinal cord deals with some basic and simple movements autonomously, while the brain can directly influence the spinal cord for coordinating and planning complex sequences of movement. Imitating this feature, WAS establishes the architecture of WSAN between centralized control and decentralized control (Fig. 2). As the lower level of 'CNS', the DAs of different PANs generate their respective responses. At the same time, the CC, the higher level, can give direct instructions to the DAs.

Components of the architecture presented above are organized in a control framework based on the term 'reflex' (Fig. 3). A reflex, often known as a spinal reflex, is a sudden, involuntary contraction of muscles in response to a stimulus, such as knee-jerk reflex and withdrawal reflex (Starr et al., 2008). As the basic units for movement (Sherrington, 1906), spinal reflexes are intrinsic and rapid, because they usually involve the spinal cord instead of the brain. As Fig. 3 shows, DSs, DAs, and related pathways constitute reflex arcs. In the reflex arcs, after being triggered by DAs (the 'spinal cord'), DSs (the 'receptors') take samples from the structure (the 'body') and pass the samples back to DAs (the 'spinal cord') through wireless pathways (the 'sensory neuron'). Then DAs (the 'spinal cord') generate outputs (the 'motor neuron') according to the intrinsic methods written in their flash memories and perform the output actuations (the 'effectors') on the structure.

The reflex that results from the lower part of the CNS is known as an inborn reflex or unconditioned reflex (UR). Some complex URs are generally known as instincts. By linking up the action of a new stimulus with a UR, a conditioned reflex (CR) is obtained. For instance, in the famous example of classical conditioning, the dog's salivary reflex to food was eventually elicited by the bell alone (Pavlov, 1927). The proposed control framework has a similar mechanism, and it is split into two hierarchies (Fig. 3). In the lower hierarchy, namely the UR, the DAs respectively respond to the DS feedback according to their own intrinsic methods, and the $\mathrm{CC}$ is rarely involved. On the other hand, the higher hierarchy, namely the $\mathrm{CR}$, gets a higher priority. The CC can directly command the DAs to perform specified actuations and ask the DAs to submit data or report their status. A key feature of the CR hierarchy lies in 
the 'conditioning'. To be specific, the CC can reserve the outputs of actuations in response to certain inputs of sensations. If the DAs have responded to an input of sampled data of the DSs in the UR mode, the CC memorizes the sampling values of the DSs and the actuations performed by the DAs. Thus, when the same or similar DS data appears next time, the CC will recall the stored case and provide the control solution to the DAs directly.

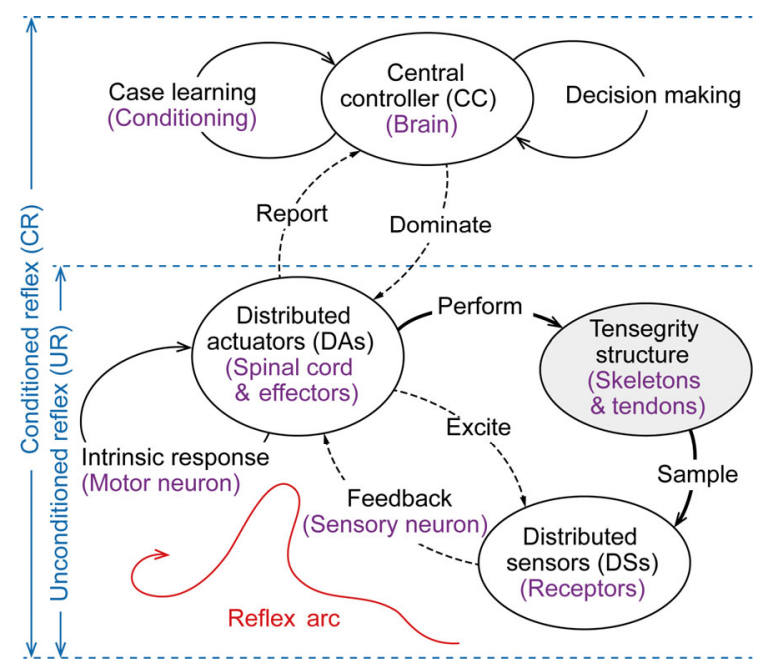

Fig. 3 Two-hierarchy control framework of WAS

\subsection{Rhythmic movement in UR and establishment of CR}

Locomotion of animals relies mainly on the sequential and rhythmic movements generated properly by the spinal cord, and the timing of muscle activations that constitute any rhythmic movement is regulated by the intrinsic properties of the spinal cord (Delcomyn, 1980; Duysens and van de Crommert, 1998; Goulding, 2009). In rhythmic movements, all or part of the body moves in a cyclic and repetitive way, as in walking, swimming, scratching, etc. The proposed control framework borrows this idea for the UR implementation. In the UR hierarchy, the DAs, i.e., the lower level of the 'CNS' (Fig. 3), can perform their intrinsic responses according to a specific rhythm, such as alternation or something more complex. The DAs can communicate with each other and create an intrinsic mechanism of the rhythm, and the $\mathrm{CC}$ can also exert additional influence on the rhythm. Therefore, on one hand, the higher level of the 'CNS' can help to regulate and stabilize the rhythmic pattern of the UR activity and, on the other hand, even if the CC may malfunction (i.e., the 'brain' does not work), the lower level of the 'CNS' is still capable of organizing the UR autonomously (Brown, 1914). Apparently this can make the proposed control framework more robust in some extreme situations.

In the control framework, the CR can be 'conditioned' through an association between the stimulus (sensations of DSs) and the response (DA actuations) of the UR, which is termed 'associative learning' (Raven and Johnson, 2002). The learning algorithm can be very intelligent with the help of some advanced techniques, such as data mining, expert systems, and reinforcement learning. It all depends on the energy and the processing capability of the CC. In fact, for this model-free control framework, the learning does not have to be complex, and the computational burden can be light or none. In the simplest scenario, the $\mathrm{CC}$ just needs to store each association for case-matching next time, which requires little processing capability. In another example, the $\mathrm{CC}$ can be trained with an ANN, which can be simple enough to run on an ordinary single-chip microprocessor.

The execution flow of the proposed control framework can be simple. It is outlined in Fig. 4 in the form of the pseudo codes for microprocessors. The interrupt function_service() will wake up the device if any applied load has been detected. After awaking, the DSs take samples from the structure, and then functions $\mathrm{CR}()$ and UR() will be called successively with the sampled $\boldsymbol{S}$. In $\mathrm{CR}()$, the decision of the

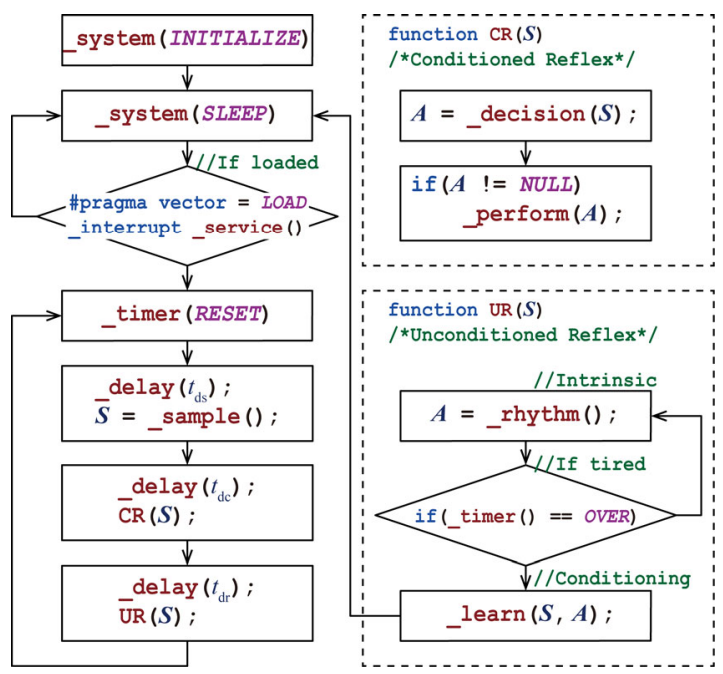

Fig. 4 Basic two-hierarchy control algorithm 
actuations, i.e., $\boldsymbol{A}$, is made according to previous experience. Then the operative mode is switched to the UR mode. In UR(), the system keeps doing intrinsic rhythmic reflexes, function_rhythm(), until the timer overflows (time to sleep). At last, after executing function learn $(\boldsymbol{S}, \boldsymbol{A})$, the system will enter the sleep state to save power.

\section{Example using the control framework: a numerical prototype}

\subsection{A simple WAS designed to maintain height under unknown loads: postural reflex}

As proof of the concept WAS proposed in Section 2.2, a triangular tensegrity prism (TTP) with embedded WSAN was designed. The TTP is composed of three struts, nine cables, one central controller (CC), three distributed actuators (DAs), and three distributed sensors (DSs) (Fig. 5). It covers a circular area of radius $0.5 \mathrm{~m}$, has a height of $1 \mathrm{~m}$, and rests on three supports. The struts and the cables are uniaxial, as stated in Section 2.2. The CC is fixed inside the structural skeleton, the three DAs are embedded in the three struts to adjust their lengths, and the three DSs are deployed on the top surface of the TTP to acquire vertical displacement data. As the root of the entire network, the CC rules the three PANs that are coordinated by the DAs. Some further details of the TTP can be found in Tables 2 and 3.

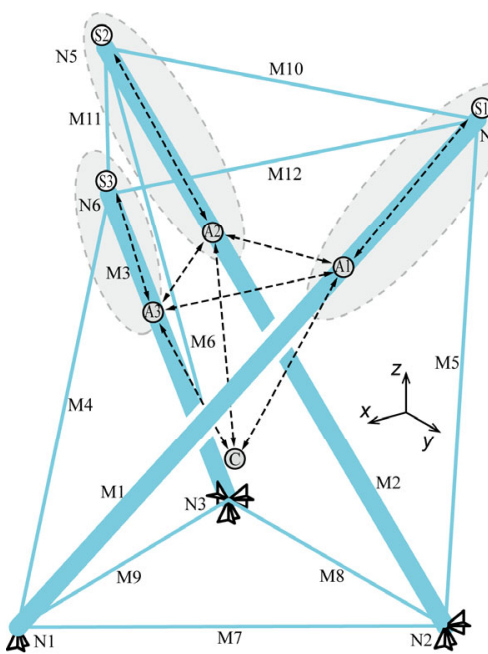

(a)
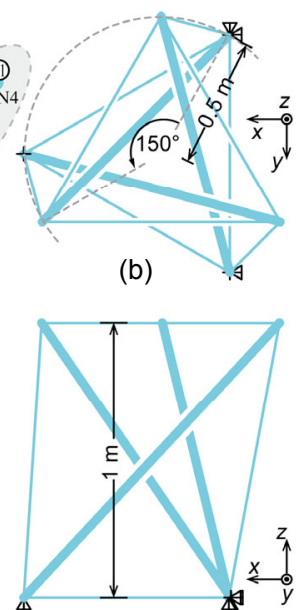

(c)
Fig. 5 A tensegrity prism with embedded WSAN: isometric view (a), top view (b), and side view (c)
The TTP is intended to have a capability of 'postural reflex' (Squire, 2013) so that it can adapt itself to maintain its height under different unknown loads (unknown to the TTP). When subjected to an external load, the TTP is always trying to keep the vertical displacements of its top surface to zero, i.e., has a 'virtual infinite' vertical stiffness.

Some values of physical parameters and initial conditions in this example are listed in Tables 2 and 3. For instance, it is assumed that the external environment is ideal. In particular, all wireless transmission is successful (no packet loss), samples of sensors are always noise free, actuator adjustments are undisturbed by the interference of the environment, and

Table 2 Specification of tensegrity

\begin{tabular}{|c|c|}
\hline Item & Description \\
\hline \multicolumn{2}{|l|}{ Global } \\
\hline Height (m) & 1.0 \\
\hline Radius of area covered (m) & 0.5 \\
\hline Gravity $\left(\mathrm{m} / \mathrm{s}^{2}\right)$ & 0 \\
\hline Damping coefficient $\left(\mathrm{s}^{-1}\right)$ & 10 \\
\hline Length of time step (s) & 0.0003 \\
\hline$n_{\mathrm{m}}, n_{\mathrm{n}}, n_{\mathrm{a}}, n_{\mathrm{s}}$ & $12,6,3,3$ \\
\hline \multicolumn{2}{|l|}{ Strut members } \\
\hline Names & M1-M3 \\
\hline Young's modulus $\left(\mathrm{kN} / \mathrm{mm}^{2}\right)$ & 206 \\
\hline Density $\left(\mathrm{kg} / \mathrm{m}^{3}\right)$ & 7900 \\
\hline Initial length (mm) & 1390.33 \\
\hline Cross section $\left(\mathrm{mm}^{2}\right)$ & 621.25 \\
\hline Allowable stress $\left(\mathrm{N} / \mathrm{mm}^{2}\right)$ & 300 \\
\hline Initial axial stress ${ }^{\mathrm{a}}\left(\mathrm{kN} / \mathrm{mm}^{2}\right)$ & 0 \\
\hline \multicolumn{2}{|l|}{ Cable members } \\
\hline Names of vertical cables & M4-M12 \\
\hline Young's modulus $\left(\mathrm{kN} / \mathrm{mm}^{2}\right)$ & 150 \\
\hline Density $\left(\mathrm{kg} / \mathrm{m}^{3}\right)$ & 7900 \\
\hline Length (vertical cables) (mm) & 1032.95 \\
\hline Length (saddle cables) (mm) & 866.03 \\
\hline Cross section $\left(\mathrm{mm}^{2}\right)$ & 28.27 \\
\hline Allowable stress $\left(\mathrm{N} / \mathrm{mm}^{2}\right)$ & 1500 \\
\hline Initial axial stress ${ }^{\mathrm{a}}\left(\mathrm{kN} / \mathrm{mm}^{2}\right)$ & 0 \\
\hline \multicolumn{2}{|l|}{ Nodes } \\
\hline Names & N1-N6 \\
\hline Type & Hinged joint \\
\hline Joint mass (kg) & 0 \\
\hline \multicolumn{2}{|l|}{ Supports } \\
\hline Type & Vertical \\
\hline Locations & $\mathrm{N} 1-\mathrm{N} 3$ \\
\hline
\end{tabular}

${ }^{a}$ The structural mechanism is infinitesimal 
Table 3 Specification of WSAN

\begin{tabular}{|c|c|}
\hline Item & Description \\
\hline \multicolumn{2}{|l|}{ Network } \\
\hline Root & $\mathrm{CC}$ \\
\hline Distributed PANs & 3 \\
\hline PAN coordinators & $\mathrm{A} 1-\mathrm{A} 3$ \\
\hline PAN ends & $\mathrm{S} 1-\mathrm{S} 3$ \\
\hline \multicolumn{2}{|l|}{ Hardware } \\
\hline Packet loss & None \\
\hline RF transmission time (s) & 0.01 \\
\hline Processing time (s) & 0 \\
\hline \multicolumn{2}{|l|}{ Distributed actuators } \\
\hline Names & $\mathrm{A} 1-\mathrm{A} 3$ \\
\hline Attached members & M1-M3 \\
\hline Related sensors & $\mathrm{S} 1-\mathrm{S} 3$ \\
\hline Type & Length adjustor \\
\hline Max stroke $(\mathrm{mm})$ & \pm 15 \\
\hline Initial position (mm) & 0 \\
\hline Extension/Shorten & Positive/Negative \\
\hline Velocity $(\mathrm{mm} / \mathrm{s})$ & 8 \\
\hline Precision (mm) & 0.01 \\
\hline Error $(\mathrm{mm})$ & 0 \\
\hline \multicolumn{2}{|l|}{ Distributed sensors } \\
\hline Names & $\mathrm{S} 1-\mathrm{S} 3$ \\
\hline Attached nodes & N4-N6 \\
\hline Type & Displacement \\
\hline Direction & Vertical (z-axis) \\
\hline Range (mm) & \pm 20 \\
\hline Resolution (mm) & 0.01 \\
\hline Noise $(\mathrm{mm})$ & 0 \\
\hline Sampling delay (s) & 0 \\
\hline \multicolumn{2}{|l|}{ Central controller } \\
\hline Learning method & $\mathrm{ANN}^{\mathrm{a}}$ \\
\hline
\end{tabular}

${ }^{a}$ A 10-layer feed-forward neural network (FNN) the time taken by analog and digital devices to process signals is too short to be noticeable. Meanwhile, limitations are set up to conform to objective reality, such as sensor resolution, actuator resolution, actuator adjusting velocity, actuator stroke range, and time cost of wireless transmission. In addition, initial conditions are given to reduce unnecessary outside factors. Specifically, the system self-weight is not considered, the structure is in the state of null self-stress equilibrium geometry (Motro, 2003) before time $t=0$ (i.e., the initial internal forces are zero), and the damping force of the structural nodes is simplified to

$$
\boldsymbol{F}_{\mathrm{d}}=\alpha_{\mathrm{d}} \boldsymbol{M} \dot{\boldsymbol{D}}
$$

where $\dot{\boldsymbol{D}}$ is $n_{\mathrm{n}} \times 3$ velocity matrix of structural nodes, and $\alpha_{\mathrm{d}}$ is the global damping coefficient (Table 2). The value of the time step is set according to the stability condition of the central difference method, as stated in Section 2.3.

\subsection{Settings}

Diverse load cases including different types (single point or multi-point), distributions (uniform or not), magnitudes, and directions (vertical or oblique) are carried out to test the TTP (Table 4). In case C1 and its subcases $\mathrm{C} 1-1-\mathrm{C} 1-9$, the TTP responds just in UR mode, while in cases $\mathrm{C} 2-\mathrm{C} 8$, in $\mathrm{CR}$ mode. The TTP is allowed to learn in cases C1-C8.

In each load case, the TTP is in the initial state of null self-stress equilibrium geometry at first. Then a set of unexpected loads is suddenly applied to the structural nodes. At that point, the TTP wakes and

Table 4 Load cases for the test of the TTP

\begin{tabular}{ccccccc}
\hline Sequence & Case $^{\mathrm{a}}$ & $\boldsymbol{f}_{1,4}(\mathrm{~N})$ & $\boldsymbol{f}_{1,5}(\mathrm{~N})$ & $\boldsymbol{f}_{1,6}(\mathrm{~N})$ & Load description & Mode \\
\hline 1 & $\mathrm{C}^{\mathrm{b}}$ & {$[0,0,0]^{\mathrm{T}}$} & {$[0,0,0]^{\mathrm{T}}$} & {$[0,0,-1000]^{\mathrm{T}}$} & Vertical, single point & UR \\
2 & $\mathrm{C} 1-1$ & {$[0,0,0]^{\mathrm{T}}$} & {$[0,0,0]^{\mathrm{T}}$} & {$[0,0,-100]^{\mathrm{T}}$} & Vertical, single point & UR \\
$\ldots$ & $\ldots$ & $\ldots$ & $\ldots$ & $\ldots$ & $\ldots$ & $\ldots$ \\
10 & $\mathrm{C} 1-9$ & {$[0,0,0]^{\mathrm{T}}$} & {$[0,0,0]^{\mathrm{T}}$} & {$[0,0,-900]^{\mathrm{T}}$} & Vertical, single point & UR \\
11 & $\mathrm{C} 2$ & {$[0,0,0]^{\mathrm{T}}$} & {$[0,0,-300]^{\mathrm{T}}$} & {$[0,0,-600]^{\mathrm{T}}$} & Vertical, 2-point, asymmetric & $\mathrm{CR}$ \\
12 & $\mathrm{C} 3$ & {$[0,0,0]^{\mathrm{T}}$} & {$[0,0,-500]^{\mathrm{T}}$} & {$[0,0,-500]^{\mathrm{T}}$} & Vertical, 2-point, symmetric & $\mathrm{CR}$ \\
13 & $\mathrm{C} 4$ & {$[0,0,-300]^{\mathrm{T}}$} & {$[0,0,-300]^{\mathrm{T}}$} & {$[0,0,-300]^{\mathrm{T}}$} & Vertical, 3-point, uniform & $\mathrm{CR}$ \\
14 & $\mathrm{C} 5$ & {$[0,0,0]^{\mathrm{T}}$} & {$[0,0,-300]^{\mathrm{T}}$} & {$[0,0,-600]^{\mathrm{T}}$} & Repeating C2 & $\mathrm{CR}$ \\
15 & $\mathrm{C} 6$ & {$[0,0,0]^{\mathrm{T}}$} & {$[0,0,0]^{\mathrm{T}}$} & {$[300,300,-600]^{\mathrm{T}}$} & Oblique, single point & $\mathrm{CR}$ \\
16 & $\mathrm{C} 7$ & {$[0,0,0]^{\mathrm{T}}$} & {$[-300,400,-500]^{\mathrm{T}}$} & {$[0,600,500]^{\mathrm{T}}$} & Oblique, 2-point, irregular & $\mathrm{CR}$ \\
17 & $\mathrm{C} 8$ & {$[-400,600,300]^{\mathrm{T}}$} & {$[900,-500,0]^{\mathrm{T}}$} & {$[500,-200,-800]^{\mathrm{T}}$} & 3-point, irregular & $\mathrm{CR}$ \\
\hline
\end{tabular}

${ }^{\mathrm{a}}$ In cases $\mathrm{C} 1-\mathrm{C} 8$, the TTP learns, while in cases $\mathrm{C} 1-1-\mathrm{C} 1-9$, it does not; ${ }^{\mathrm{b}}$ The $1 \mathrm{st}$ UR without any experience 
starts the timer $(t=0)$. The stabilization time variables in Fig. 4 , namely $t_{\mathrm{ds}}, t_{\mathrm{dc}}$, and $t_{\mathrm{dr}}$, are set to $1.5 \mathrm{~s}, 0.5 \mathrm{~s}$, and $2 \mathrm{~s}$, respectively.

Some functions presented in Fig. 4 are defined specifically for the TTP (Fig. 6). In function $\boldsymbol{A}=$ rhythm(), once the DA of the $k$ th PAN is excited (activated), it will keep responding intrinsically according to the DS feedback, which provides a linear output feedback control:

$$
\Delta a_{k}=c_{\mathrm{t}} s_{k}
$$

where $\forall k \in\left\{1,2, \ldots, n_{\mathrm{a}}\right\} \quad\left(n_{\mathrm{a}}=3\right)$, and $c_{\mathrm{t}}=-0.5$. As stated in the macro definition, a critical displacement $d_{\mathrm{c}}(=0.05 \mathrm{~mm})$ is defined as the criterion whether the DAs should enter the state of inhibition or not. Once the extent of the feedback $s_{k}$ is less than $d_{\mathrm{c}}$, the $k$ th DA inhibits its excitation and excites the coordinator of the next PAN, i.e., the $(k+1)$ th $\mathrm{DA}$, and then the $(k+2)$ th, $\ldots$, the $n_{\mathrm{a}}$ th $\mathrm{DA}$, so that excitatory reflex happens in one PAN after another. The system repeats these sequential excitatory reflexes until the timer overflows, which takes on a regular rhythm. The CC simply uses a 10-layer feed-forward neural network (FNN) $\boldsymbol{N}_{\mathrm{f}}$ for case learning and decision making. Function _learn $(\boldsymbol{S}, \boldsymbol{A})$ adds a new group of input $\boldsymbol{S}$ and output $\boldsymbol{A}$ into the case libraries $\left(\boldsymbol{L}_{\mathrm{i}}\right.$ and $\left.\boldsymbol{L}_{\mathrm{o}}\right)$ and trains $\boldsymbol{N}_{\mathrm{f}}$. Function $\boldsymbol{A}=$ decision $(\boldsymbol{S})$ directly gives the output of $\boldsymbol{N}_{\mathrm{f}}$ according to an input $\boldsymbol{S}$.

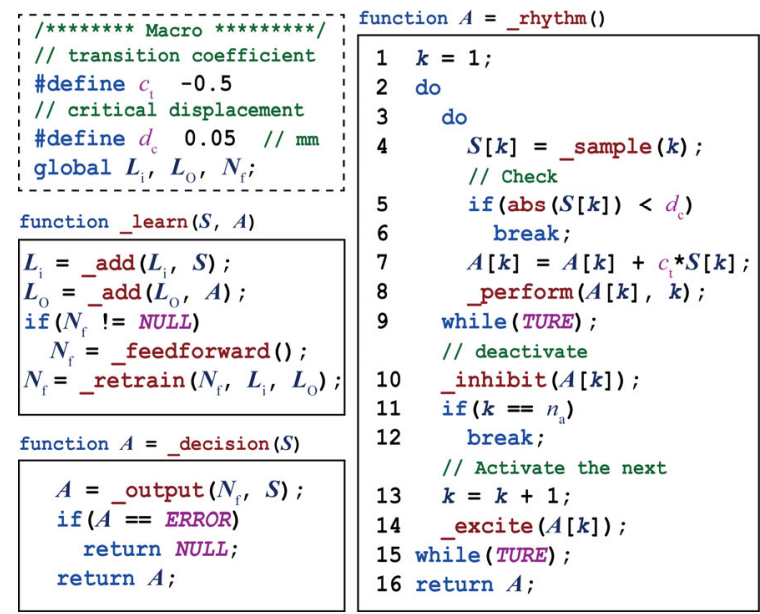

Fig. 6 Intrinsic action and learning mode of the TTP

It can be seen that $d_{\mathrm{c}}$ actually determines the control accuracy. The final value of $s_{k}$ will always be in the interval of $\left(-d_{\mathrm{c}}, d_{\mathrm{c}}\right)$. Thus, the lower $d_{\mathrm{c}}$ is, the more accurate the control effect will be, and the more time the control process will take. The coefficient $c_{\mathrm{t}}$ determines the feedback extent of each single intrinsic response. The lower $c_{t}$ is, the finer the actuations will be. Actually, there can be some other more complex feedback forms than Eq. (42). It all depends on the specific layout of WAS and the requirement of the designers.

\subsection{The first UR}

Because there is no knowledge in the 'brain' (the $\mathrm{CC}$ ) at the beginning of the simulation, case $\mathrm{C} 1$ is the first pure UR test. Fig. 7 shows two contour plots (isometric view) of vertical displacement in case $\mathrm{C} 1$. The upper plot shows the status when the load has been applied and UR has not yet started ( $t=3.99 \mathrm{~s})$, and the lower one is the result at $t=39.99 \mathrm{~s}$ when all PANs have been in a state of inhibition. Apparently, at last UR has made all vertical displacements of the top surface to be within the criterion $d_{\mathrm{c}}(0.05 \mathrm{~mm})$. That is to say, the vertical deformation of the top surface has reverted. Some more details about the first UR are stated as follows.

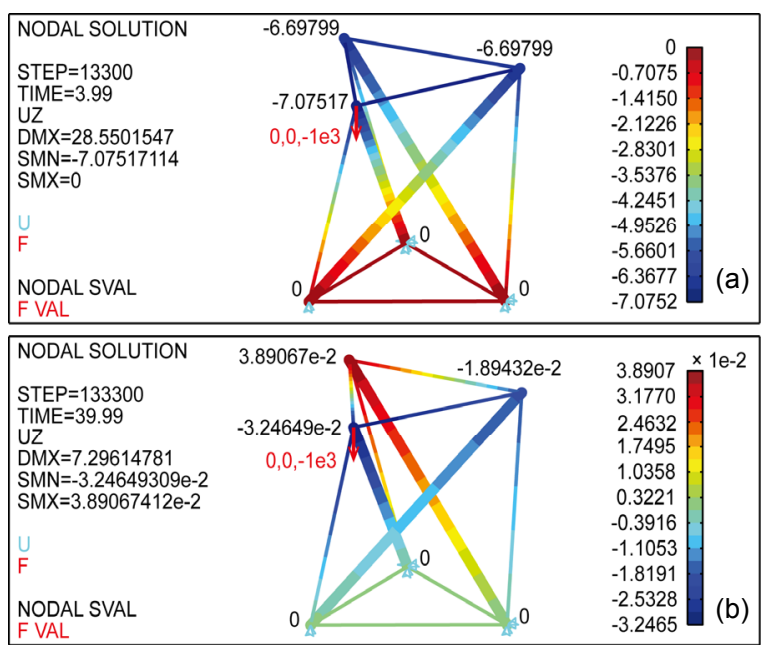

Fig. 7 Contour plots of vertical displacement before (a) and after (b) UR in case $\mathrm{C1}$ (unit: $\mathrm{mm}$ )

Fig. 8 shows the wireless transmission record in case $\mathrm{C} 1$ (from $t=0 \mathrm{~s}$ to $t=40.0 \mathrm{~s}$ ), containing the record of the CC and the DAs. This can be viewed as the representation of signal transmission among the 'CNS' of the TTP. On the ordinate, 1 stands for 
transmitting, and 0 stands for not. At $t=1.5 \mathrm{~s}$, the CC asks each DA to update and submit the DS sample. From $t=4.0 \mathrm{~s}$, the DAs start to act one by one. While one DA is excited (activated), the other two are not. In the rhythmic movement, one excited DA keeps asking its corresponding DS for performing feedback until the DA is inhibited. Then the DA passes its excitement to the next, and in the meantime, it submits a report to the $\mathrm{CC}$ for confirmation. As time goes by, the alternation among the DAs becomes more and more frequent, which means the rhythmic movement gets closer to a stable state.

The rhythmic movement can be surveyed more clearly in Fig. 9. The DAs perform alternately, and the DSs also sample in turn. In each PAN, the DA actuation and the DS sample change synchronously with each other. One difference is that the displacements do not change alternately one node after another. No matter which DA performs, it can induce that all the three nodal displacements fluctuate synchronously. In fact, this phenomenon has been stated in Section 2.1, which is also the reason why UR motion should be rhythmic (orderly). If each DA reflexes casually on its own without any rhythm, the actions of the DAs will interact with each other, and the structure shape may vary disorderedly.

As time goes by, the actuation extents of the DAs and the sampled values of the DSs both start to decrease, and the fluctuation of the displacements reduces gradually (Fig. 9). Approximately at $t=35.0 \mathrm{~s}$,

(a)

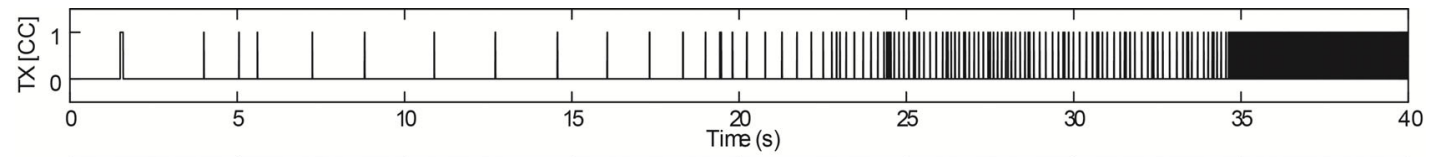

(b)

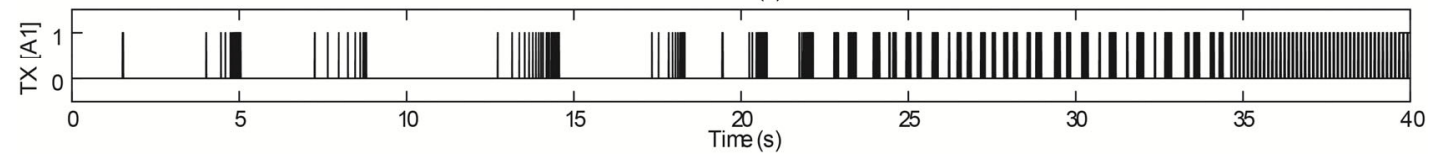

(c)

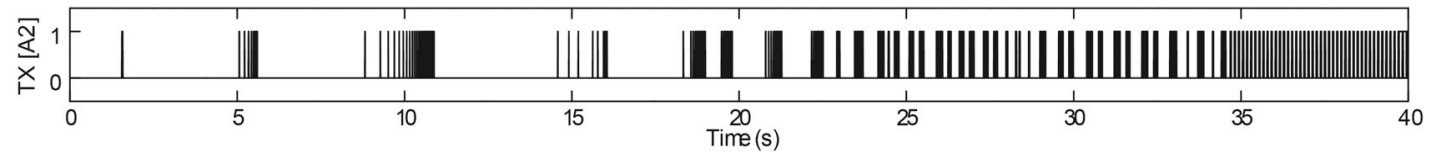

(d)

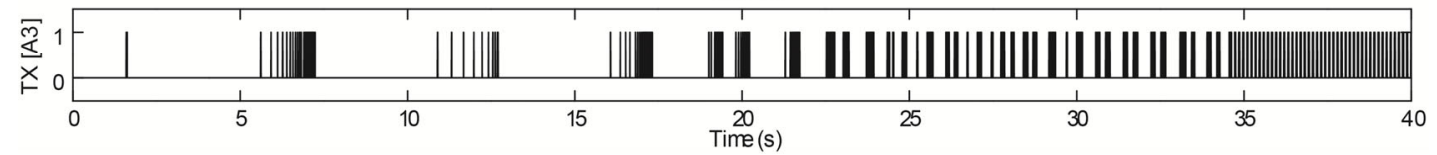

Fig. 8 Time-history data in case C1: wireless transmission of the CC (a) and DAs (b)-(d)
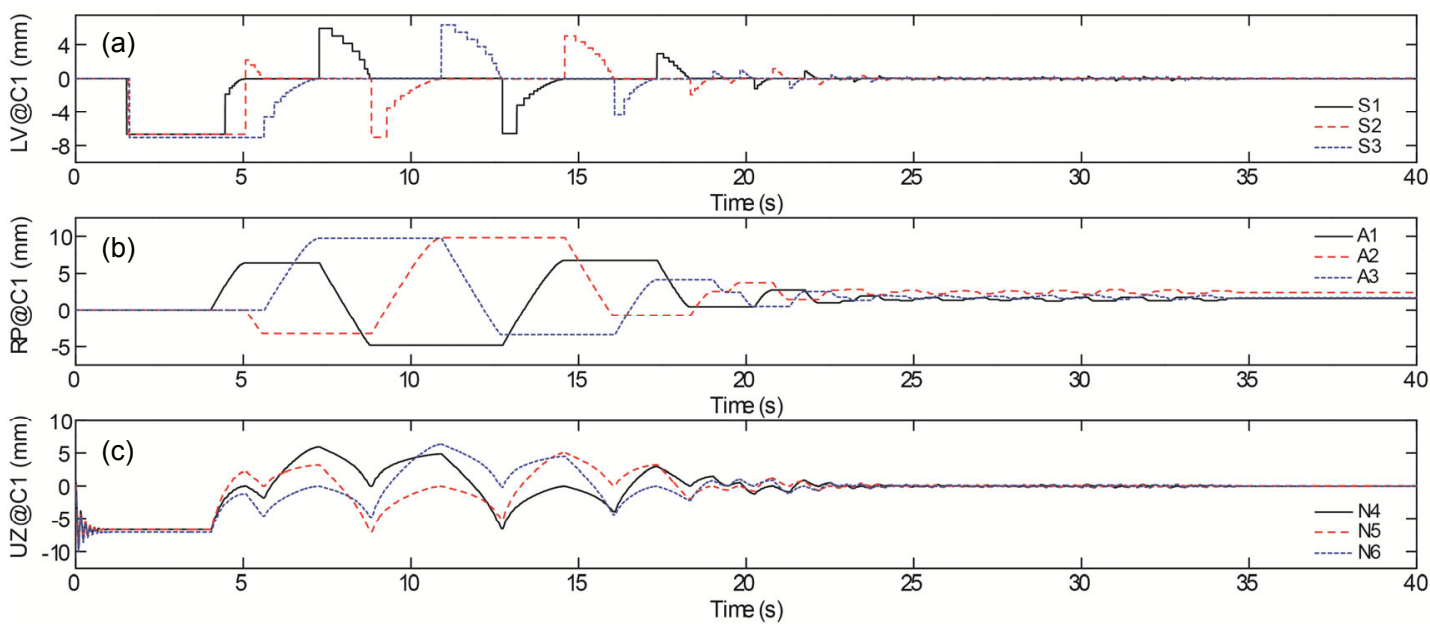

Fig. 9 Time-history data in case C1: sampled values of DSs (a), actuations of DAs (b), and nodal vertical displacements (c) 'LV' is short for last updated value of sampling displacement; 'RP' is short for relative position in actuator stroke (i.e., adjustment amount); ' $\mathrm{UZ}$ ' stands for displacement on $z$-axis direction; ' $\mathrm{C} 1$ ' means case $\mathrm{C} 1$ 
the DAs all stop performing (enter a state of inhibition), and the displacements do not vary any more.

The UR process can be seen more visually in Fig. 10. An actuation path of the rhythmic movement starts from the initial state (before any actuation is performed), wriggles around, narrows the encirclement, and then stabilizes to an inhibition state (Fig. 10a). The inhibition state is the state of $t \geq t_{\mathrm{i}}$ when all the DAs have entered the state of inhibition, where $t_{\mathrm{i}}$ is called the inhibition time. From a macroscopic view (Fig. 10b), the top surface slants, swings, and finally reverts back to the original height (within the margin of error).

Fig. 11 shows some internal force results of structural members including M1, M4, and M7. The stress values of the three members fluctuate synchronously with the curves of time-displacement in Fig. 9. A negative correlation can be found between strut stress and cable stress. Moreover, compared with the initial state, the stress magnitudes in struts and cables have significantly increased after entering the stable state. In other words, to maintain the top surface height, the TTP has to sacrifice some internal force margin to neutralize the structural vertical deformation.

\subsection{Performance}

In case $\mathrm{C} 1$ and its subcases $\mathrm{C} 1-1-\mathrm{C} 1-9$, the TTP responds only in the UR mode. The actuation amount and inhibition time are related to the magnitudes of loads in these cases (Fig. 12). Basically, both the extent of actuation and the required time of inhibition are positively correlated with the load magnitudes. The maximum and minimum values of the actuations determine the maximum stroke of the actuators. Both maximum stroke and inhibition time indicate the control efficiency. Without any previous experience, the larger the effect that is caused by external loads, the more energy and time it takes to control.

For different types of loads, the TTP successfully returns its top surface back to the original height (Fig. 13). In fact, the accuracy of the reversion depends on the displacement criterion $d_{\mathrm{c}}$. The smaller $d_{\mathrm{c}}$ is, the more accurate the reversion will be.

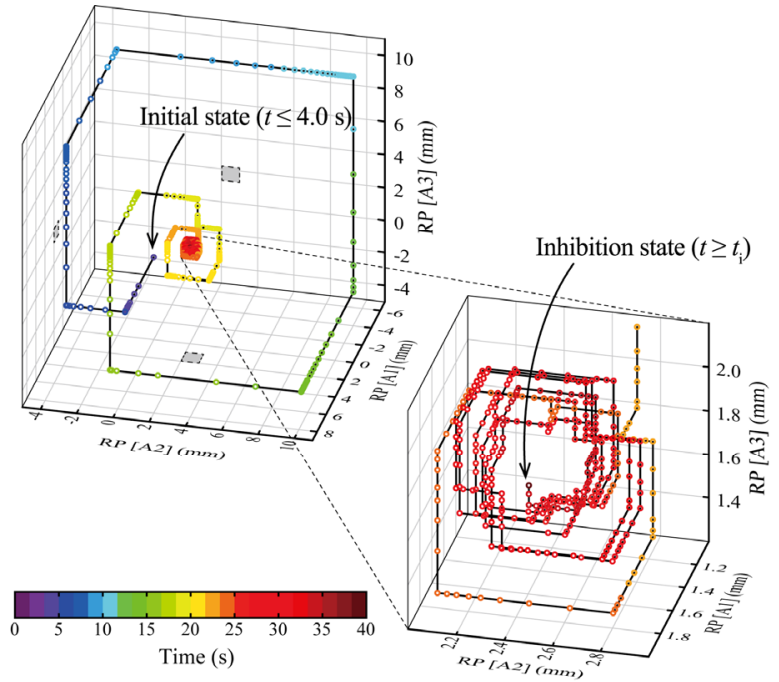

(a)

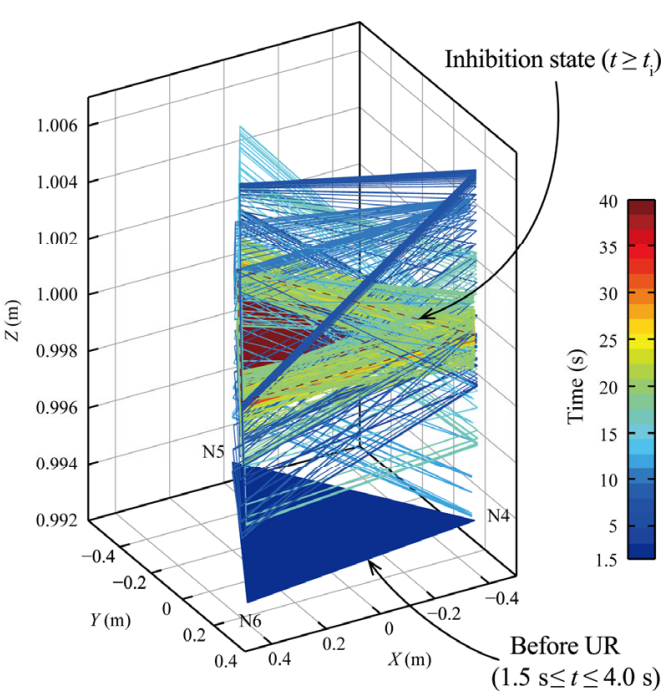

(b)

Fig. 10 Process of the UR in case C1: (a) convergence of the actuations; (b) reversion of the top surface

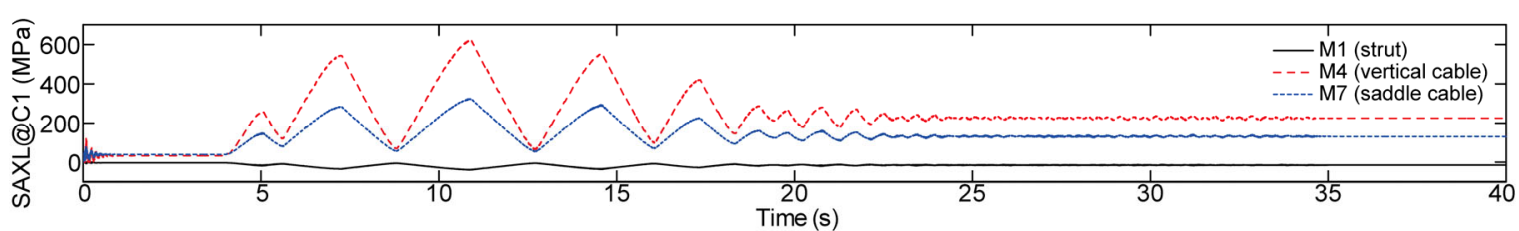

Fig. 11 Time-history data in case C1: axial stress (SAXL) of structural members 
Unlike pure UR in case $\mathrm{C} 1$, the $\mathrm{CR}$ solution $\boldsymbol{A}$ $(t=2.0 \mathrm{~s})$ can be generated in cases $\mathrm{C} 2-\mathrm{C} 8$ according to the input $\boldsymbol{S}$ ( $t=1.5 \mathrm{~s}$ ) (Table 5$)$. With the previous experience, $t_{\mathrm{i}}$ in cases $\mathrm{C} 2-\mathrm{C} 8$ reduces significantly compared with case $\mathrm{C} 1$. It means that the DAs enter the inhibition state sooner. Apparently, because of the FNN in the CC, the full process with CR is more efficient than with pure UR.

With the experience of case $\mathrm{C} 1$, the rhythmic movement inhibits more quickly in case C2 (Fig. 14a). For similar types of loads, the control performance improves with more cases carried out in sequence
(Figs. 14b and 14c). In case C5 particularly, the DAs do not need to act any more after the CR performs, because the CR solution given by the FNN is exactly the same as the eventual actuation of case $\mathrm{C} 2$.

For those load types that have not been experienced before, the TTP seems somewhat inexperienced (Figs. 14d and 14e). The more dissimilar the load types are from the previous experience, the less effective the CR solution is, and then the longer time it takes to inhibit. Nevertheless, the CR mode is much faster than the pure UR model. In a word, the more the TTP practices, the more sophisticated it will be.
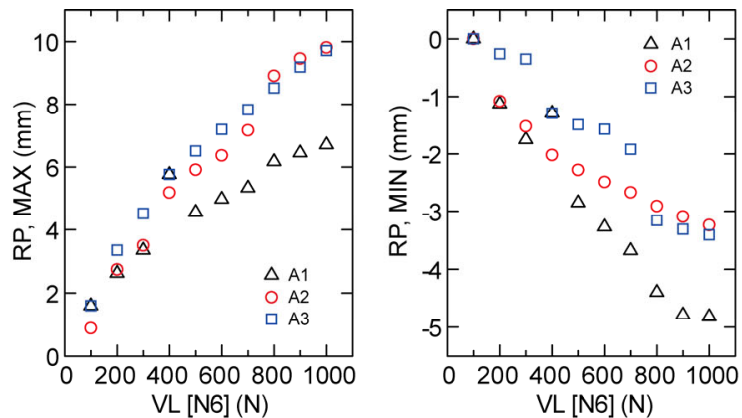
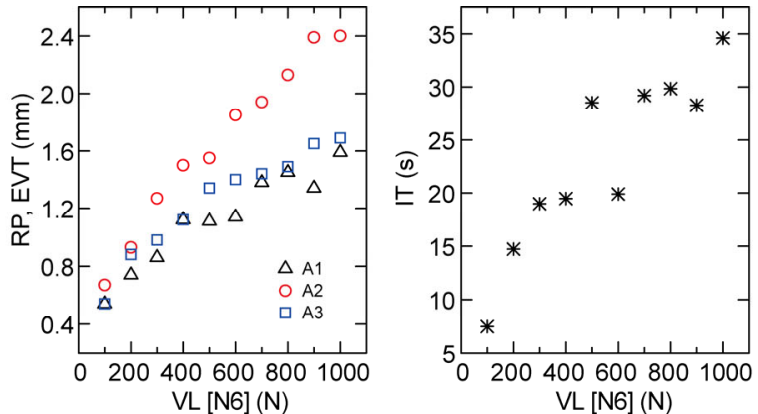

Fig. 12 Actuations and inhibition times of single vertical load cases

'VL' is short for vertical load; 'MAX' means maximum; 'MIN' means minimum; 'EVT' means eventual results of the inhibition state; 'IT' is short for inhibition time

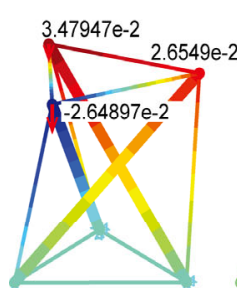

C2

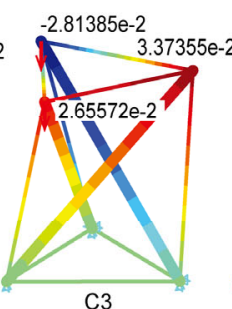

C3

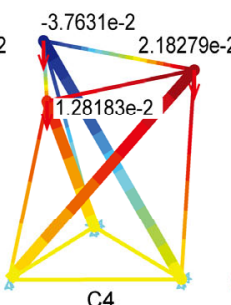

C4

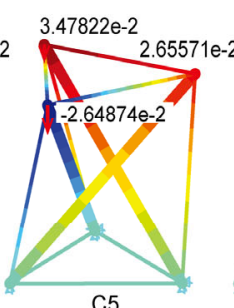

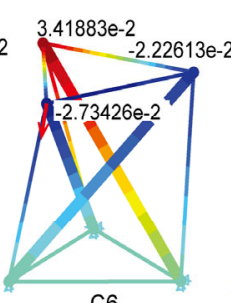

C6

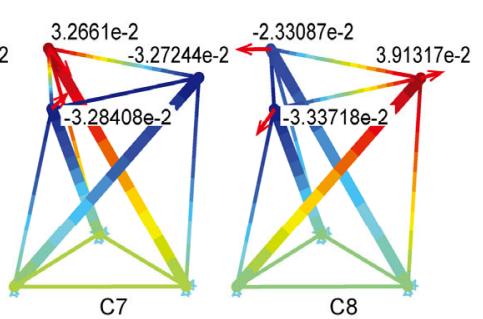

Fig. 13 Vertical displacement plot of the inhibition state: cases C2-C8 (unit: $\mathbf{m m}$ )

Table 5 Performance summary of cases C1-C8

\begin{tabular}{cccccc}
\hline Case & $\boldsymbol{S}^{\mathrm{a}}(t=1.5 \mathrm{~s})$ & $\boldsymbol{A}^{\mathrm{b}}(t=2.0 \mathrm{~s})$ & $\boldsymbol{A}\left(t \geq t_{\mathrm{i}}\right)$ & $\boldsymbol{S}\left(t \geq t_{\mathrm{i}}\right)$ & $t_{\mathrm{i}}(\mathrm{s})$ \\
\hline C1 & {$[-6.70,-6.70,-7.07]^{\mathrm{T}}$} & - & {$[1.59,2.40,1.69]^{\mathrm{T}}$} & {$[-0.02,0.04,-0.03]^{\mathrm{T}}$} & 34.6035 \\
C2 & {$[-6.47,-6.59,-6.70]^{\mathrm{T}}$} & {$[1.59,2.40,1.69]^{\mathrm{T}}$} & {$[1.80,2.01,1.61]^{\mathrm{T}}$} & {$[0.03,0.03,-0.03]^{\mathrm{T}}$} & 8.4795 \\
C3 & {$[-6.70,-6.89,-6.88]^{\mathrm{T}}$} & {$[1.57,2.22,1.71]^{\mathrm{T}}$} & {$[1.89,2.12,1.70]^{\mathrm{T}}$} & {$[0.03,-0.03,0.03]^{\mathrm{T}}$} & 8.3955 \\
C4 & {$[-6.59,-6.59,-6.59]^{\mathrm{T}}$} & {$[1.81,1.85,1.65]^{\mathrm{T}}$} & {$[1.72,1.81,1.87]^{\mathrm{T}}$} & {$[0.02,-0.04,0.01]^{\mathrm{T}}$} & 5.2665 \\
C5 & {$[-6.47,-6.59,-6.70]^{\mathrm{T}}$} & {$[1.80,2.01,1.61]^{\mathrm{T}}$} & {$[1.80,2.01,1.61]^{\mathrm{T}}$} & {$[0.03,0.03,-0.03]^{\mathrm{T}}$} & 2.2695 \\
C6 & {$[-6.65,-6.66,-7.04]^{\mathrm{T}}$} & {$[1.70,2.56,1.57]^{\mathrm{T}}$} & {$[1.59,2.46,1.70]^{\mathrm{T}}$} & {$[-0.02,0.03,-0.03]^{\mathrm{T}}$} & 5.5005 \\
C7 & {$[-6.81,-6.52,-6.64]^{\mathrm{T}}$} & {$[1.71,2.28,1.64]^{\mathrm{T}}$} & {$[1.63,1.61,2.09]^{\mathrm{T}}$} & {$[-0.03,0.03,-0.03]^{\mathrm{T}}$} & 7.4295 \\
C8 & {$[-6.09,-6.69,-6.90]^{\mathrm{T}}$} & {$[1.96,2.17,1.83]^{\mathrm{T}}$} & {$[1.94,2.84,1.09]^{\mathrm{T}}$} & {$[0.04,-0.02,-0.03]^{\mathrm{T}}$} & 8.0085 \\
\hline
\end{tabular}

${ }^{\mathrm{a}} \boldsymbol{S}=\left[s_{1}, s_{2}, s_{3}\right]^{\mathrm{T}}$ (unit: $\mathrm{mm}$ ); ${ }^{\mathrm{b}} \boldsymbol{A}=\left[a_{1}, a_{2}, a_{3}\right]^{\mathrm{T}}$ (unit: $\mathrm{mm}$ ) 

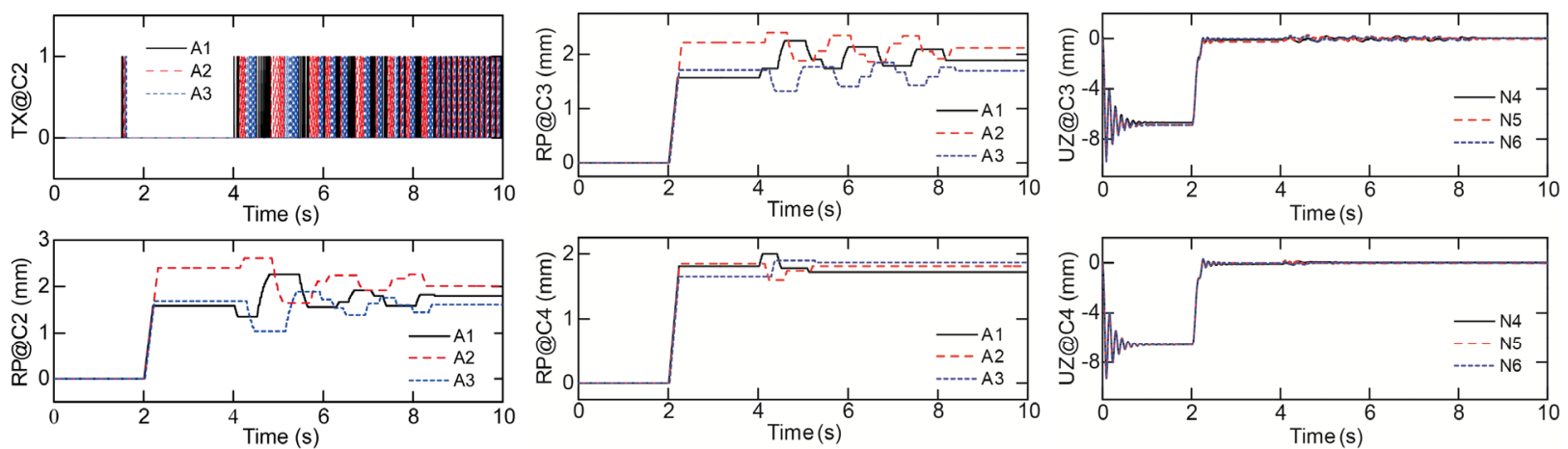

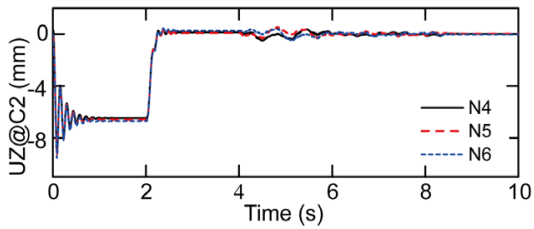

(a)

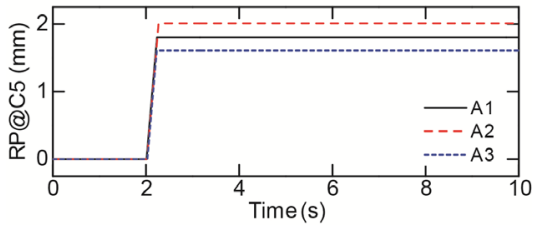

(b)

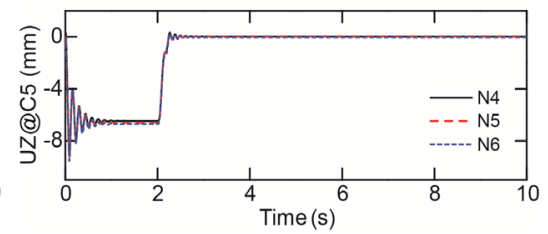

(c)
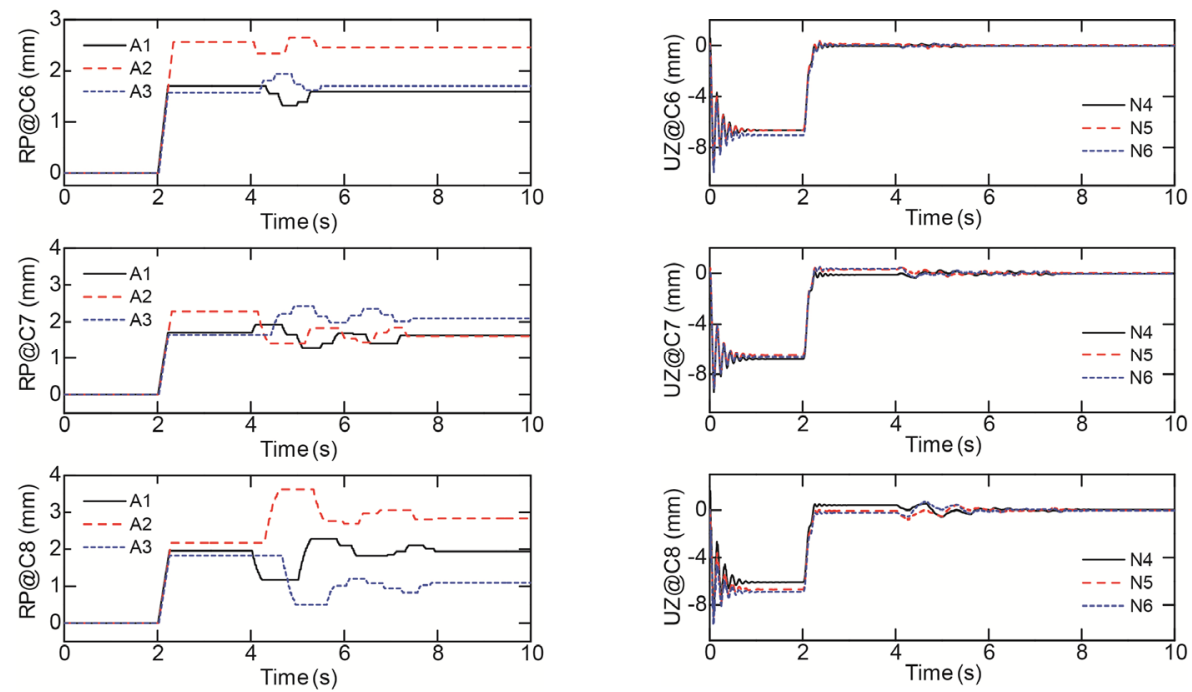

(d)

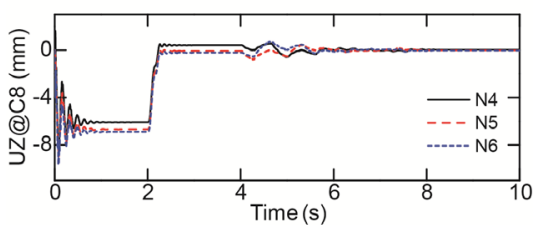

(e)

Fig. 14 Time-history data of different load cases

(a) The wireless transmission log, the actuation amounts, and the vertical displacements in case $\mathrm{C} 2$; (b) The actuation amounts in cases C3-C5; (c) The vertical displacements in cases C3-C5; (d) The actuation amounts in cases C6-C8; (e) The vertical displacements in cases $\mathrm{C} 6-\mathrm{C} 8$

\section{Conclusions}

Inspired by the locomotion of animals and the control strategies of multi-legged robots, this paper presents a method to enhance the shape control of AS in civil engineering. A concept of compound system, WAS, has been proposed and modeled. In WAS, AS is integrated with a WSAN. A two-hierarchy bioinspired control framework is designed for WAS by imitating reflex activity and rhythmic movements of animals. A typical example of a triangular tensegrity prism that aims to maintain its original height has been carried out for verification. The results demonstrate that the deformed structure successfully reverts to its original height after being subjected to different types, distributions, magnitudes, or directions of unknown loads. The performance of the proposed control framework is also discussed. In summary, the WAS with the proposed bio-inspired control framework possesses the following attractive features compared with recent related work of AS: 
1. Instant response and little computational burden. The proposed control framework is modelfree and does not need stochastic search methods or a large number of FEM solving processes. The hardware can provide the control solution directly according to built-in parameters.

2. Less dependence on hardware performance and a more robust system. Because of avoidance of heavy computational burden, most low-cost microprocessors can meet the requirement for hardware performance. Meanwhile, multiple distributed controllers greatly reduce the risk that the whole system might break down.

3. Greater adaptability to different types of loads. For the proposed framework, the load conditions do not have to be known or prescribed to the computer or the human controllers, because there is no need for the numerical FEM calculation during the control process. In the framework, the types and extents of loads are allowed to be totally unknown.

4. Greater flexibility for design of control strategy. Compared with wired control systems, the proposed WAS with WSAN can change its communication topology without plugging or unplugging wires when the layout or the control strategy of WAS system is modified.

5. Fewer sources of error (model-free and closed-loop control). The proposed model-free control framework eliminates the error caused by the difference between the numerical model and the real structure. The closed-control mechanism in the framework guarantees that the control effect only depends on the parameter setting and sensor accuracy.

6. Easier installation or deployment, easier maintenance, lower cost, etc. Using wireless devices avoids a vast wiring workload, and can save time and cost for installation or replacement.

Moreover, if applicable, the proposed control framework can act as a supplementary means for improving the efficiency and accuracy of control frameworks based on a common stochastic search. Although the proposed concept has been verified in this study, there are still some limitations for shape control of WAS:

1. To achieve the stable bio-inspired feature, the structural form and device parameters of WAS re- quire delicate design, which limits the universality of the proposed control framework.

2. Similar to a common stochastic search, the control solution provided by the proposed control framework also has the limitation that although it is certainly feasible, it is not guaranteed to be the optimum solution.

3 . The stability of the proposed control framework has not been proved yet.

Overcoming the limitations and implementing an experimental demonstration will be the main orientation of further research. Besides, considering the potential impacts of WAS, there is room for improvement in the future. For example:

1. The situations that WAS adapts to can be extended from loading to rapid temperature changes, pre-stress loss, or structural damage.

2. Shape control of WAS is expected to extend from single-object control to multi-object control.

3. The proposed control framework can be enhanced and enriched by more advanced learning algorithms, more complex design of rhythmic patterns or self-evolution algorithms.

4. WAS provides a possibility for creating largescale active grid-structures.

\section{References}

Adam, B., Smith, I.F.C., 2006. Learning, self-diagnosis and multi-objective control of an active tensegrity structure. In: Pandey, M., Xie, W.C., Xu, L. (Eds.), Advances in Engineering Structures, Mechanics \& Construction. Springer Netherlands, Dordrecht, the Netherlands, p.439448. http://dx.doi.org/10.1007/1-4020-4891-2_36

Adam, B., Smith, I.F.C., 2007a. Self-diagnosis and self-repair of an active tensegrity structure. Journal of Structural Engineering, 133(12): 1752-1761. http://dx.doi.org/10.1061/(asce)0733-9445(2007)133:12 (1752)

Adam, B., Smith, I.F.C., 2007b. Tensegrity active control: multiobjective approach. Journal of Computing in Civil Engineering, 21(1):3-10. http://dx.doi.org/10.1061/(asce)0887-3801(2007)21:1(3)

Adam, B., Smith, I.F.C., 2008. Active tensegrity: a control framework for an adaptive civil-engineering structure. Computers \& Structures, 86(23-24):2215-2223. http://dx.doi.org/10.1016/j.compstruc.2008.05.006

Akyildiz, I.F., Kasimoglu, I.H., 2004. Wireless sensor and actor networks: research challenges. Ad Hoc Networks, 2(4):351-367. 
http://dx.doi.org/10.1016/j.adhoc.2004.04.003

Angellier, N., Dubé, J., Quirant, J., et al., 2012. Behavior of a double-layer tensegrity grid under static loading: identification of self-stress level. Journal of Structural Engineering, 139(6): 1075-1081.

http://dx.doi.org/10.1061/(asce)st.1943-541X.0000710

Atzori, L., Iera, A., Morabito, G., 2010. The internet of things: a survey. Computer Networks, 54(15):2787-2805. http://dx.doi.org/10.1016/j.comnet.2010.05.010

Bathe, K.J., Wilson, E.L., 1976. Numerical Methods in Finite Element Analysis. Prentice-Hall, Upper Saddle River, NJ, USA.

Belytschko, T., Liu, W.K., Moran, B., 2000. Nonlinear Finite Elements for Continua and Structures. Wiley, New York.

Bliss, T.K., Iwasaki, T., Bart-Smith, H., 2008. CPG control of a tensegrity morphing structure for biomimetic applications. Advances in Science and Technology, 58:137-142. http://dx.doi.org/10.4028/www.scientific.net/AST.58.137

Brown, T.G., 1914. On the nature of the fundamental activity of the nervous centres; together with an analysis of the conditioning of rhythmic activity in progression, and a theory of the evolution of function in the nervous system. The Journal of Physiology, 48(1):18-46. http://dx.doi.org/10.1113/jphysiol.1914.sp001646

Cao, X.H., Chen, J.M., Xiao, Y., et al., 2010. Buildingenvironment control with wireless sensor and actuator networks: centralized versus distributed. IEEE Transactions on Industrial Electronics, 57(11):3596-3605. http://dx.doi.org/10.1109/TIE.2009.2029585

Chen, J., Cao, X., Xiao, Y., et al., 2008. Simulated annealing for optimisation with wireless sensor and actuator networks. Electronics Letters, 44(20):1208-1209. http://dx.doi.org/10.1049/el:20081574

Chen, J., Cao, X., Cheng, P., et al., 2010. Distributed collaborative control for industrial automation with wireless sensor and actuator networks. IEEE Transactions on Industrial Electronics, 57(12):4219-4230. http://dx.doi.org/10.1109/TIE.2010.2043038

Delcomyn, F., 1980. Neural basis of rhythmic behavior in animals. Science, 210(4469):492-498. http://dx.doi.org/10.1126/science.7423199

Djouadi, S., Motro, R., Pons, J., et al., 1998. Active control of tensegrity systems. Journal of Aerospace Engineering, 11(2):37-44. http://dx.doi.org/10.1061/(asce)0893-1321(1998)11:2(37)

Domer, B., Smith, I., 2005. An active structure that learns. Journal of Computing in Civil Engineering, 19(1):16-24. http://dx.doi.org/10.1061/(asce)0887-3801(2005)19:1(16)

Domer, B., Fest, E., Lalit, V., et al., 2003a. Combining dynamic relaxation method with artificial neural networks to enhance simulation of tensegrity structures. Journal of Structural Engineering, 129(5):672-681. http://dx.doi.org/10.1061/(asce)0733-9445(2003)129:5(672)

Domer, B., Raphael, B., Shea, K., et al., 2003b. A study of two stochastic search methods for structural control. Journal of Computing in Civil Engineering, 17(3):132-141. http://dx.doi.org/10.1061/(asce)0887-3801(2003)17:3(132)

Duysens, J., van de Crommert, H.W.A.A., 1998. Neural control of locomotion; Part 1. The central pattern generator from cats to humans. Gait \& Posture, 7(2): 131-141.

http://dx.doi.org/10.1016/S0966-6362(97)00042-8

Fest, E., Shea, K., Domer, B., et al., 2003. Adjustable tensegrity structures. Journal of Structural Engineering, 129(4):515-526.

http://dx.doi.org/10.1061/(asce)0733-9445(2003)129:4(515)

Fest, E., Shea, K., Smith, I., 2004. Active tensegrity structure. Journal of Structural Engineering, 130(10):1454-1465. http://dx.doi.org/10.1061/(asce)0733-9445(2004)130:10 (1454)

Goulding, M., 2009. Circuits controlling vertebrate locomotion: moving in a new direction. Nature Reviews Neuroscience, 10(7):507-518. http://dx.doi.org/10.1038/nrn2608

IEEE Computer Society, 2011. IEEE Standard for Local and Metropolitan Area Networks-Part 15.4: Low-rate Wireless Personal Area Networks (LR-WPANs). IEEE, New York.

Ijspeert, A.J., 2008. Central pattern generators for locomotion control in animals and robots: a review. Neural Networks, 21(4):642-653. http://dx.doi.org/10.1016/j.neunet.2008.03.014

Kanchanasaratool, N., Williamson, D., 2002. Modelling and control of class NSP tensegrity structures. International Journal of Control, 75(2):123-139. http://dx.doi.org/10.1080/00207170110070563

Kandel, E., 2013. Principles of Neural Science. McGraw-Hill Education, New York.

Kawaguchi, K.I., Hangai, Y., Pellegrino, S., et al., 1996. Shape and stress control analysis of prestressed truss structures. Journal of Reinforced Plastics and Composites, 15(12): 1226-1236. http://dx.doi.org/10.1177/073168449601501204

Korkmaz, S., Ali, N.B.H., Smith, I.F.C., 2011. Determining control strategies for damage tolerance of an active tensegrity structure. Engineering Structures, 33(6):19301939.

http://dx.doi.org/10.1016/j.engstruct.2011.02.031

Korkmaz, S., Ali, N.B.H., Smith, I.F.C., 2012. Configuration of control system for damage tolerance of a tensegrity bridge. Advanced Engineering Informatics, 26(1):145-155. http://dx.doi.org/10.1016/j.aei.2011.10.002

Luo, Y.Z., Yang, C., 2014. A vector-form hybrid particleelement method for modeling and nonlinear shell analysis of thin membranes exhibiting wrinkling. Journal of Zhejiang University-SCIENCE A (Applied Physics \& Engineering), 15(5):331-350. http://dx.doi.org/10.1631/jzus.A1300248

Lynch, J.P., 2007. An overview of wireless structural health monitoring for civil structures. Philosophical Transactions of the Royal Society A: Mathematical, Physical and Engineering Sciences, 365(1851):345-372. 
http://dx.doi.org/10.1098/rsta.2006.1932

Miura, K., Furuya, H., 1988. Adaptive structure concept for future space applications. AIAA Journal, 26(8):995-1002. http://dx.doi.org/10.2514/3.10002

Morris, R.G.M., Fillenz, M., 2003. Neuroscience: the Science of the Brain. British Neuroscience Association, Liverpool, UK.

Motro, R., 2003. Tensegrity: Structural Systems for the Future. Kogan Page Science, London.

Pavlov, I.P., 1927. Conditioned Reflexes: an Investigation of the Physiological Activity of the Cerebral Cortex. Oxford University Press, Oxford.

Raven, P.H., Johnson, G.B., 2002. Biology. McGraw-Hill, New York.

Shea, K., Fest, E., Smith, I.F.C., 2002. Developing intelligent tensegrity structures with stochastic search. Advanced Engineering Informatics, 16(1):21-40. http://dx.doi.org/10.1016/S1474-0346(02)00003-4

Sherrington, C., 1906. The Integrative Action of the Nervous System. Yale University Press, New Haven, USA.

Skelton, R.E., Sultan, C., 1997. Controllable tensegrity: a new class of smart structures. Smart Structures and Materials 1997: Mathematics and Control in Smart Structures, San Diego, CA, USA, p.166-177. http://dx.doi.org/10.1117/12.276535

Smith, I.F.C., 2003. From active to intelligent structures. Proceedings of the Seventh International Conference on the Application of Artificial Intelligence to Civil and Structural Engineering, Egmond aan Zee, the Netherlands, p.3-4.

Smith, I.F.C., 2009a. Control enhancements of a biomimetic structure. Journal of Information Technology in Construction, 14:229-237.

Smith, I.F.C., 2009b. A control framework for a biomimetic structure. EUROPIA09, Paris, p.153-172.

Soong, T., Manolis, G., 1987. Active structures. Journal of Structural Engineering, 113(11):2290-2302. http://dx.doi.org/10.1061/(asce)0733-9445(1987)113:11 (2290)

Spencer, B.F., Ruiz-Sandoval, M.E., Kurata, N., 2004. Smart sensing technology: opportunities and challenges. Structural Control and Health Monitoring, 11(4):349-368. http://dx.doi.org/10.1002/stc.48

Squire, L.R., 2013. Fundamental Neuroscience. Academic Press, San Diego, CA, USA.

Stankovic, J., 2008. When sensor and actuator networks cover the world. ETRI Journal, 30(5):627-633. http://dx.doi.org/10.4218/etrij.08.1308.0099

Starr, C., Taggart, R., Evers, C., et al., 2008. Biology: the Unity and Diversity of Life. Cengage Learning, Belmont, CA, USA.

Straser, E.G., Kiremidjian, A.S., 1998. A modular, wireless damage monitoring system for structures. Report No. 129, Blume Earthquake Engineering Center, Stanford University, Stanford, CA, USA.

Sultan, C., Skelton, R.E., 1997. Integrated design of control- lable tensegrity structures. Adaptive Structures and Material Systems: Proceedings of the 1997 ASME International Mechanical Engineering Congress and Exposition, Dallas, TX, USA, p.27-35.

Swartz, R.A., Lynch, J.P., 2009. Strategic network utilization in a wireless structural control system for seismically excited structures. Journal of Structural Engineering, 135(5):597-608. http://dx.doi.org/10.1061/(asce)st.1943-541X.0000002

Veuve, N.W., Dalil Safaei, S., Smith, I.F.C., 2014. Toward development of a biomimetic tensegrity footbridge. Sixth World Conference on Structural Control and Monitoring, Barcelona, Spain.

Wada, B.K., 1990. Adaptive structures-an overview. Journal of Spacecraft and Rockets, 27(3):330-337. http://dx.doi.org/10.2514/3.26144

Wang, Y., Law, K., 2011. Structural control with multi-subnet wireless sensing feedback: experimental validation of time-delayed decentralized H-infinity control design. Advances in Structural Engineering, 14(1):25-39. http://dx.doi.org/10.1260/1369-4332.14.1.25

Wang, Y., Swartz, R.A., Lynch, J.P., et al., 2007. Decentralized civil structural control using real-time wireless sensing and embedded computing. Smart Structures and Systems, 3(3):321-340. http://dx.doi.org/10.12989/sss.2007.3.3.321

Wu, Q., Liu, C., Zhang, J., et al., 2009. Survey of locomotion control of legged robots inspired by biological concept. Science in China Series F: Information Sciences, 52(10): 1715-1729. http://dx.doi.org/10.1007/s11432-009-0169-7

$\mathrm{Xu}, \mathrm{X}$., Luo, Y., 2008. Multi-objective shape control of prestressed structures with genetic algorithms. Proceedings of the Institution of Mechanical Engineers, Part G: Journal of Aerospace Engineering, 222(8):1139-1147. http://dx.doi.org/10.1243/09544100JAERO394

$\mathrm{Xu}, \mathrm{X}$., Luo, Y., 2009. Non-linear displacement control of prestressed cable structures. Proceedings of the Institution of Mechanical Engineers, Part G: Journal of Aerospace Engineering, 223(7):1001-1007. http://dx.doi.org/10.1243/09544100JAERO455

Yang, C., Shen, Y.B., Luo, Y.Z., 2014. An efficient numerical shape analysis for light weight membrane structures. Journal of Zhejiang University-SCIENCE A (Applied Physics \& Engineering), 15(4):255-271. http://dx.doi.org/10.1631/jzus.A1300245

Yao, J.T., 1972. Concept of structural control. Journal of the Structural Division, 98(7):1567-1574.

Yu, J.Z., Tan, M., Chen, J., et al., 2014. A survey on CPGinspired control models and system implementation. IEEE Transactions on Neural Networks and Learning Systems, 25(3):441-456. http://dx.doi.org/10.1109/TNNLS.2013.2280596

Zuk, W., 1968. Kinetic structures. Civil Engineering, 38(12): 62. 


\section{中文概要}

\section{题 目: 集成无线传感器-执行器网络的主动结构: 一种 仿生控制框架}

目 的: 主动结构的几何形状控制一直是结构控制领域的 研究前沿。为满足形状控制目标, 一个主要问题 就是如何求解主动构件的执行量。以随机搜索算 法为核心的基于模型的控制方法逐渐成为主流， 但仍存在若干需改善之处, 如计算量大、实时性 差、不能很好应对未知荷载作用以及实际结构与 数值模型间存在差异等。本研究旨在寻求一种控 制框架，使其能够在某些场合下具备更好的控制 性能。

创新点: 1. 提出一类主动结构混合系统一一集成无线传感 器-执行器网络的主动结构 (WAS) ; 2. 通过模 仿动物反射活动以及节律运动, 提出 WAS 的两 层级仿生控制框架。
方 法: 1. 将无线传感器-执行器网络引入主动结构, 组成 混合系统, 建立离散的基本模型（图 1）；2. 结 合仿生思想, 按照两层级控制框架编制基本控制 流程（图 3和 4)； 3. 通过仿真模拟，将无线传 感器-执行器网络嵌入主动三棱柱张拉整体结构, 运用仿生控制框架对张拉整体结构在多种工况 下进行形状控制, 验证所提概念和方法的可行性 与有效性（图 7 和 13）。

结 论: 1 . 与以随机搜索算法为主的基于模型的形状控制 方法相比, 本文所提出的混合系统及其仿生控制 框架, 计算量极小, 因此可快速应对外部作用的 变化; 2. 对于未知荷载作用, 本文提出的仿生控 制框架无需进行荷载识别, 因此适应性更强; 3. 由于不依赖于有限元模型, 该仿生控制框架避 免了来自实际结构与数值模型的误差, 因此控制 精度更高。

关键词: 主动结构; 无线传感器-执行器网络; 形状控制; 仿生控制 